\title{
Molecular and cellular pathways contributing to brain aging
}

\author{
Aliabbas Zia ${ }^{1}$, Ali Mohammad Pourbagher-Shahri ${ }^{2}$, Tahereh Farkhondeh ${ }^{3,4}$ and Saeed Samarghandian ${ }^{5^{*}}$ (D)
}

\begin{abstract}
Aging is the leading risk factor for several age-associated diseases such as neurodegenerative diseases. Understanding the biology of aging mechanisms is essential to the pursuit of brain health. In this regard, brain aging is defined by a gradual decrease in neurophysiological functions, impaired adaptive neuroplasticity, dysregulation of neuronal $\mathrm{Ca}^{2+}$ homeostasis, neuroinflammation, and oxidatively modified molecules and organelles. Numerous pathways lead to brain aging, including increased oxidative stress, inflammation, disturbances in energy metabolism such as deregulated autophagy, mitochondrial dysfunction, and IGF-1, mTOR, ROS, AMPK, SIRTs, and p53 as central modulators of the metabolic control, connecting aging to the pathways, which lead to neurodegenerative disorders. Also, calorie restriction (CR), physical exercise, and mental activities can extend lifespan and increase nervous system resistance to age-associated neurodegenerative diseases. The neuroprotective effect of $C R$ involves increased protection against ROS generation, maintenance of cellular $\mathrm{Ca}^{2+}$ homeostasis, and inhibition of apoptosis. The recent evidence about the modem molecular and cellular methods in neurobiology to brain aging is exhibiting a significant potential in brain cells for adaptation to aging and resistance to neurodegenerative disorders.
\end{abstract}

Keywords: Brain, Aging, Oxidative stress, Inflammation

\section{Introduction}

Aging is a complex and multifactorial phenomenon characterized by a gradual decrement in physiological actions and behavioral capacity. Aging happens at molecular, cellular, and histological levels in different organs, particularly at the central nervous system (CNS) and particularly the brain [1-3]. Advancing of age alters the biological, chemical, and physical functions of neurons leading to memory impairment, altered behaviors, loss of cognition functions, dementia, and impaired immune responses. Also, aging is one of the main risk factors for common neurodegenerative disorders such as Parkinson's disease (PD), amyotrophic lateral sclerosis (ALS), Alzheimer's disease $(\mathrm{AD})$, and stroke $[4,5]$. Brain aging has been linked with subtle alterations in the structure and

*Correspondence: samarghandians1@nums.ac.ir

${ }^{5}$ Noncommunicable Diseases Research Center, Neyshabur University of Medical Sciences, Neyshabur, Iran

Full list of author information is available at the end of the article function of neurons in specific neuronal circuits rather than only high rates of neuron loss. The compensation mechanism for neuron loss in the aging brain is through expanding dendritic arbors and synaptic connections. The brain in age-associated neurodegenerative diseases loses dendritic arbors and synaptic contacts. It thus cannot compensate for the neuronal loss [6,7].

Brain aging in the various species of mammals allocates several common characteristics, such as synaptic atrophy, dendritic regression in pyramidal neurons, accumulation of fluorescent pigments, cytoskeletal abnormalities, a decline of striatal dopamine receptors, and reactive microglia and astrocytes [8]. Despite the identification of brain aging characteristics in several neuronal networks of the brain, the exact responsible molecular mechanisms are still unclear.

Studies have suggested several major signaling pathways and molecular targets, including oxidative stress, metabolism dysfunction, deregulated autophagy, telomere shortening, mitochondrial dysfunction, cellular 
calcium homeostasis, and systemic inflammation modulation of aging and lifespan in a wide range of species expanding from yeast to mammals. Gene expression analysis studies have defined some of these signaling and molecular pathways and led to conserved evolutionary alterations through aging $[6,9,10]$. Further, brain imaging technologies such as magnetic resonance imaging (MRI) and positron emission tomography (PET) are allowing the study of neuronal circuits and cognitive networks in the aging brain [11].

Several environmental factors have been identified to affect brain aging mechanism, including the rate of structural alteration. Calorie restriction (CR) has been shown to delay functional and structural decreases by aging in some animal model organisms such as rodents and monkeys $[12,13]$. CR reduces daily calorie intake below the energy requirements while keeping optimal nutrients for health without being malnutritional [14, 15]. It was first shown by McCay et al. in 1935 that male and female rats with CR had increased lifespan while having a retarded growth [16].

Considerable evidence indicates the beneficial effects of physical exercise on healthy aging, even in old age [17-19]. Several epidemiological studies have investigated the effects of physical exercise on cognition in older age. A systematic review of 127 observational studies showed that physical exercise decreased the relative risk of cognition decline with risk or hazard ratios in the range of 0.6 and 1.6 in the general population over 50 years old in economically developed countries [20]. A systematic review of 33,816 non-demented individuals older than 65 years, followed between 1 and 12 years, who were enrolled in 13 prospective studies showed that 3210 individuals developed cognitive decline. Individuals with high levels of physical exercise had reduced cognitive decline with a hazard ratio of 0.62 (95\% CI 0.54 to 0.70 ; pb0.00001), and low to moderate physical exercise reduced the risk of cognitive decline with a hazard ratio of 0.65 (95\% CI 0.57 to 0.75 ; pb0.00001) compared with sedentarism [21].

Physical exercise has been shown to protect against brain aging by inducing angiogenesis and increasing the blood flow to the brain [22-25]. The underlying mechanisms for these effects of physical exercise are thought to be through inducing vascular endothelial growth factor (VEGF) [26, 27]. Animal researches showed that physical exercise initiates neurogenesis, evidenced by increased proliferation and survival of hippocampal cells ranging from young to old age animals [28-31]. Furthermore, physical exercise was shown to induce and maintain LTP. Also, it enhanced short-term memory in the DG by exhibiting hippocampal neurogenesis in animals [28, 32, 33].
Studies from rodents showed that physical exercise could counter age-related cognition impairments by attenuating and even reversing the age-induced decreased neurogenesis [32, 34]. However, one of the limitations for beneficial effects of physical exercise in rodents was the age of animals as very old rodents did not benefit from the physical exercise [35]. It has been shown that physical exercise protects against AD pathology via suppressing amyloid deposition and reducing Ab-dependent neuronal cell death [36-38]. Also, type, frequency, and amount of calorie intake and physical exercise can significantly affect brain health during the lifetime. For instance, aerobic exercise enhances hippocampal volume, while excessive calorie consumption, inadequate physical activities, and obesity accelerate hippocampal atrophy [39].

By increasing dopamine receptors' expression in the striatum, physical exercise combat age-related cognitive decline [40]. In the same concept, physical exercise in the form of treadmill running protected against PD by recovering the dopamine depletion in the striatum of hemiparkinsonian rats [41].

Mental activities can exhibit neuroprotection and neuroplasticity enhancement during aging. It has been shown that treads of mental engagements such as educational level, occupational complexity, or cognitive lifestyle activities can reduce the risk of cognitive impairments [42, 43]. Interestingly, mental activities in individuals with a high-risk genetic background (e.g., apolipoprotein E4 carriers) for the cognitive decline can delay the clinical manifestation of cognitive decline [4446]. A meta-analysis showed that individuals with high mental activities impose lower cognitive decline risks in the future [47]. Studies have investigated mental activities in the concept of environmental enrichment, which comprises augmented living conditions, including more space, increased social contact, increased cognitive stimulation through toys, wheels, mazes, and more opportunities for physical activity [48].

Several aging theories have been suggested to describe the process of aging and, in particular the brain aging. However, neither of them seems to fill the gap. Hence, we discuss molecular, cellular, and neuro-anatomical changes integrated through brain aging and age-associated neurodegenerative disease. The role of critical metabolic pathways has also been discussed.

\section{Role of oxidative stress in brain aging}

In the 1950s, Harman's free radical theory of aging suggested that reactive oxygen species (ROS) cause oxidative damage in cellular macromolecules, including DNA, proteins, and lipids, leading to decreased biochemical and physiological function through aging [49, 
50]. In mammals, ROS origins include xanthine oxidase, NADPH oxidase, nitric oxide synthase (NOS), peroxidase, cyclooxygenase and lipoxygenase, mitochondrial respiration, cytochrome $\mathrm{p} 450 \mathrm{~s}$, and endoplasmic reticulum [51, 52]. Free radicals are a subset of ROS species possessing unpaired electrons. These free radicals include peroxyl $\left(\mathrm{RO}_{2} \cdot\right)$, nitric oxide (NO$\left.\cdot\right)$, hydroxyl radical (HO.), superoxide anion $\left(\mathrm{O}^{2-} \cdot\right)$, and hydroperoxyl $\left(\mathrm{HO}_{2} \cdot\right)$. Other ROS like peroxynitrite $(\mathrm{ONOO}-)$, ozone $\left(\mathrm{O}_{3}\right)$, hypochlorous acid ( $\left.\mathrm{HOCl}\right)$, and hydrogen peroxide $(\mathrm{H} 2 \mathrm{O} 2)$ are non-radical derivatives that have role in oxidative stress [53].

The hemostasis of intracellular ROS is mediated via the activity of numerous enzymatic and non-enzymatic systems with the cellular detoxification function, cumulatively called antioxidants.

The nuclear factor erythroid 2-related factor 2 (Nrf2 ) is the main transcription factor and also one of the primary regulators of the antioxidant signaling, such as transcription of endogenous antioxidant enzymes including glutathione $(\mathrm{GSH})$, glutathione reductase $(\mathrm{GR})$, glutathione peroxidase (GPx), catalase (CAT), superoxide dismutase (SOD) and heme oxygenase-1 (HO-1). This antioxidant system is collectively the primary defense system that neutralizes ROS generation inside the cells $[54,55]$.

Mitochondria are considered a significant origin of ROS through aging [56]. Harman, in the 1970s, reviewed his free radical theory after the discovery of the fact that mitochondria can produce water from oxygen at the end of the electron transport chain (ETC), a procedure that, when impaired, lead to a high generation of mitochondrial ROS (mtROS), which is associated with high levels of mitochondrial DNA (mtDNA) mutations and respiratory chain deficiency [57].

In D. melanogaster, the signaling function of mtROS produced by the respiratory chain (RC) positively affects lifespan, helping to extend longevity [58]. Knockdown of the SOD2 gene and enhanced mtROS appears to extend lifespan in C. elegans. In contrast, up-regulation of catalase enhances oxidative stress resistance and does not extends lifespan [59, 60]. Also, dietary supplements of antioxidants decrease the lifespan of worms [61]. Interestingly, the genetic modification that increased mtROS and ROS-induced injury in mice did not accelerate the progression of aging; however, it promoted the appearance of different age-associated disorders [62]. The reason is that cytosolic ROS and mROS have opposite effects, and cytosolic ROS is more harmful [63]. In detail, the hydrogen peroxide generated with beneficial purposes in mitochondria spreads across the membrane of mitochondria, releases to the cytosol, and functions as an oxidative agent involved in aging [64]. This evidence proposes that ROS effects depend on their concentration and space [63].

The types of ROS in neurons include superoxide anion produced by the respiratory chain and via different oxidases, hydroxyl radical generated via the hydrogen peroxide reaction with $\mathrm{Cu}^{+}$or $\mathrm{Fe}^{2+}$, and $\mathrm{NO}$ produced in response to increased intracellular levels of $\mathrm{Ca}^{2+}$ [65]. Also, in the mitochondria, NO is generated from L-citrulline and L-arginine in a NOS reaction. This enzyme has three different isoforms with various tissue localizations. Endothelial NOS (eNOS) is expressed in the vascular endothelium, cellular $\mathrm{Ca}^{2+}$-dependent neuronal NOS (nNOS) is expressed in glial cells (microglial cells, astrocytes, and macrophages) and $\mathrm{Ca}^{2+}$-independent inducible NOS (iNOS), which is expressed in a wide range of cells and tissues. NO is involved in several essential procedures within the CNS, like memory formation and the regulation of cerebral blood flow (CBF) to provide a sufficient supply of blood to the brain. Also, it has a pivotal role in modulating the immune system, including the regulation of cytokine generation [66].

During brain aging, enhanced ROS generation and decreased antioxidants result in redox imbalance, causing age-related disorders. In a mouse model of AD, voluntary physical exercise suppressed oxidative stress in the brain, evidenced by reduced oxidative stress biomarkers and down-regulated pro-inflammatory and pro-oxidative mediators [67]. NO-dependent oxidative damage promotes apoptosis in motor neurons. It causes vascular cognitive impairment through the aging of the cerebral cortex. Further, NO-mediated neuronal injury is involved in several neuronal disorders such as PD [68]. ROS can deteriorate cellular function via the modification of proteins and lipids in the brain. The alterations in the composition of phospholipids provide evidence that ROS-induced lipid peroxidation happens in brains involved in CNS dysfunction, like cognitive impairment, in aged humans and animals. Accordingly, enhanced production of malondialdehyde (MDA) in brains has been proposed as a hallmark of aging. It has been reported that the levels of MDA were remarkably increased in the aged rat hippocampus [69]. Also, MDA on electron microscopy forms cap-like linear deposits connected with intracellular neuronal lipofuscin.

In contrast, glial MDA deposits surrounded vacuoles in the CA4 region of the human hippocampus [70]. On the other hand, no remarkable enhancement of MDA-modified proteins was found in the brain of the aged rat, which could be because MDA-modified protein reacts with lipid peroxidation products cross-link with each other [71]. In the cerebral cortex and cerebellum of aged rats, diminished amounts of poly saturated fatty acid (PUFA) 
and enhanced amounts of monounsaturated fatty acids have been reported [72].

The capability to maintain long-term potentiation (LTP) is commonly used as the main factor of cognitive function. Decreased levels of arachidonic acid (AA) in the aged rat brain have been associated with impairment of LTP. This proposes that oxidative reduction of AA levels might associate with cognitive impairment in rats [73, 74]. It was reported that brains of aged dogs exhibit lipid peroxidation product 4-hydroxynonenal (HNE) accumulation, linked with neurofibrillary tangles (NFTs) and amyloid deposits [75]. Post-synaptic AMPA receptors are implicated in the LTP process [76]. It has been shown that after five weeks of environmental enrichment, LTP and LTD were increased [77]. Upregulation of post-synaptic AMPA receptors and increased LTP-related functions have been shown to occur after environmental enrichment in mice with NMDA defects [78]. However, in mice with upregulated NMDA receptors, environmental enrichment did not affect functions related to LTP [79].

Many investigations exhibited that brain aging was connected with the accumulation of oxidized protein, characterized by elevated carbonyl residues [80, 81]. Also, it was exhibited that levels of protein carbonyl were enhanced in different regions of the brain in various animal models, like the occipital and frontal cortex in aged humans [81], the forebrain in Wistar rats [82], brain homogenates of aged canine models [80] and the cortex in Brown Norway rats [83] and Mongolian gerbils [84]. Following the idea that oxidative stress-mediated enhanced protein carbonyls contribute to dementia detected in some older adults, in the aged learning-impaired rats, only proteins in a $65-\mathrm{KDa}$ band were detected to have high levels of carbonyl residues [85]. Decreased olfaction is one of the common characteristics of aging. Investigations of model organisms like mice exhibit that amounts of protein carbonylation in astrocytes and neurons and protein nitration in blood vessels are enhanced in the olfactory bulb through aging [68].

Decreased antioxidant defense and disability to eliminate oxidatively damaged biomolecules can accelerate the aging of organisms. In confirming, genetic reduction at the levels of SOD2 in D. melanogaster and mice results in the accelerated onset of age-related neurological characteristics, such as neuronal DNA damage, motor dysfunction, and neurodegeneration [86, 87]. One of the major antioxidant defense complexes is the heat-shock response (HSR), a cellular response that elevates the number of molecular chaperones to diminish the adverse effects on proteins caused via stressors, oxidative stress, increased temperatures, and heavy metals. Long-term exposure to extreme stress conditions is detrimental. Activation of heat-shock protein (HSP) synthesis can lead to enhanced stress tolerance and cellular protection against neuronal injury [88-90]. In the CNS, HSP synthesis is induced via exposure to cytotoxic drugs, heavy metals or amino acid analogs, and changes in the intracellular redox state [88, 89]. Therefore, the heat-shock response has a crucial role in providing a cytoprotective environment in the different metabolic disruptions, like age-associated neurodegenerative disorders and aging. Also, in aged animals, oxidative modification of proteins leads to protein aggregation, cellular damage, diminished organ function, and ultimately to apoptotic cell death. HSP has a pivotal role in maintaining cells from injury via defense against protein denaturation. Hence, alterations of the activity and expression of HSPs are associated with the denaturation of proteins during aging [91-93].

Similarly, the GSH system is necessary for the cellular detoxification of ROS in brain cells. A compromised GSH system in the brain has been associated with oxidative stress in neurological disorders [94-96]. Interestingly recent evidence shows that GSH has pivotal extracellular functions in the brain. Astrocytes seem to have a crucial role in the metabolism of GSH in the brain since the release of GSH from astrocytes is essential for providing precursors for GSH synthesis in neurons [97]. Between the various brain cells investigated in vitro, only cultured astrocytes produce and release significant GSH and GSSG through oxidative stress [98]. Recent experiments propose a direct association between diminished levels of GSH by oxidative stress and rapid up-regulation of $\mathrm{HO}-1$ in a different range of cells such as human fibroblasts, rat cardiomyocytes, and rat brains [99].

Furthermore, enhanced generation of $\mathrm{NO}$ can lead to alterations in intracellular levels of GSH. Also, in cultures of astroglial cells, induction of iNOS declines total GSH, whereas increasing GSSG, and this effect was eliminated by pretreatment of glial cells with inhibitors of NOS [100]. In addition, an increased intracellular GSH before treatment of endothelial cells to NO donors almost eliminates activation of the HO-1 cascade, which exhibits that GSH can counteract NO via stimulating HO-1 [89]. Ultimately, these data support the idea that the decrease of antioxidant defense systems is as essential as ROS production in the injury of the aging brain (Fig. 1).

\section{Mitochondrial dysfunction and brain aging}

Mitochondria are defined as the 'energy powerhouse of the cell' because they enable cells to produce more ATP than they could via oxidative phosphorylation. Mitochondria also provide biochemical energy for cellular function and are vital to our survival [101]. Mitochondria can grow larger, combine with other mitochondria, and 


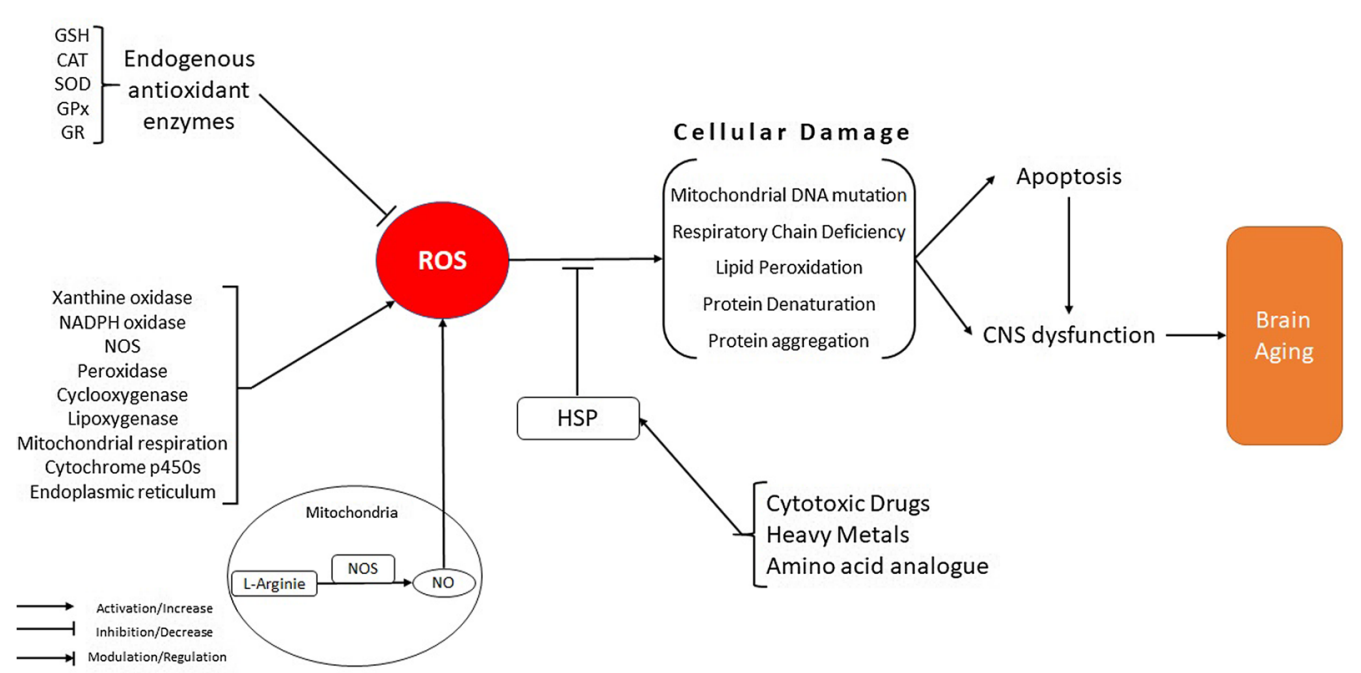

Fig. 1 Role of oxidative stress in brain aging

divide. Also, dysfunctional mitochondria can be removed via lysosomes [102, 103].

Mitochondria have crucial roles in $\mathrm{Ca}^{2+}$ homeostasis within the cells and as the origin of signals that modulate transcription of the nuclear gene [104-106]. Also, it has been reported that mitochondria have a non-energetic role in the modulation of metabolism, apoptosis, and aging [107-109].

Most mitochondria genes are conveyed to the nuclear DNA (nDNA). The mtDNA encodes 13 subunits of oxidative phosphorylation. The remaining 76 subunits are encoded via nDNA made in the cytosol and then transferred to the mitochondria, which show functional interaction among both genomes [110, 111]. The functional communication between nuclear and mitochondrial DNA is essential for mitochondrial function and health. The lack of this interaction causes dysfunction of mitochondria and the decline of ATP synthesis [109].

The regulation of mitochondria happens mostly via peroxisome proliferator-activated receptor gamma coactivator 1-alpha (PGC-1 $\alpha$ ) and PGC-1 $\beta$, which respond to alterations in nutrient levels, like AMP/ATP and NAD + / NADH ratio (regulated through AMPK and SIRT1). The PGC- $1 \alpha / \beta$ expression has an essential role in the biogenesis of mitochondria $[112,113]$. Also, the mitochondrial function can be modulated via Hypoxia-inducible factor 1 alpha (HIF-1 $\alpha$ ). HIF- $1 \alpha$ is recruited to mitochondria in response to oxidative stress. Mitochondrial HIF- $1 \alpha$ maintains against oxidative stress-induced apoptosis. HIF- $1 \alpha$ in mitochondria decreases ROS levels and reverses mitochondrial damage [114]. In the model organism $C$. elegans, the HIF- $\alpha$-mediated ROS is the major lifespan determinant. However, the exact mechanisms involved are still not completely elucidated (Fig. 2) [115]. An animal study showed that calorie restriction or aerobic exercise similarly increased PGC- $1 \alpha$ levels and spatial memory in mice. The combination of calorie restriction and aerobic exercise or physical exercise alone showed a higher increment in PGC-1 $\alpha$ levels and spatial memory [116].

The brain's vulnerability towards mitochondrial dysfunction makes it a target of aging-induced progressive decline in mitochondrial function [117]. Mitochondria are spread across the axons and dendrites of neurons. They produce ATP that acts as a neurotransmitter in both central and peripheral nervous systems. ATP is also involved in chemical neurotransmission and also cellular maintenance and repair [118].

Axonal transport is essential for neurons' regular action and survival, transferring newly made substances from the soma to target cells across the axon and conveying trophic factors from synaptic terminals to the soma. Axonal transport is mediated via motor proteins that walk across microtubules. Fast axonal transport needs persistent energy through long distances to fuel the molecular motors that transport vesicles. The motors that are involved in fast axonal transport need ATP generated via mitochondria all across the axon. Therefore, impairment of mitochondrial ATP generation can disturb axonal transport, and disturbances in transport can intervene with mitochondrial trafficking, leading to axonal degeneration (Table 1).

Mitochondrial oxidative phosphorylation is the critical origin of energy supply and axonal transport in the cortical projection neurons (CPNs), which degenerate in AD [117]. Thus, these neurons are highly vulnerable to 


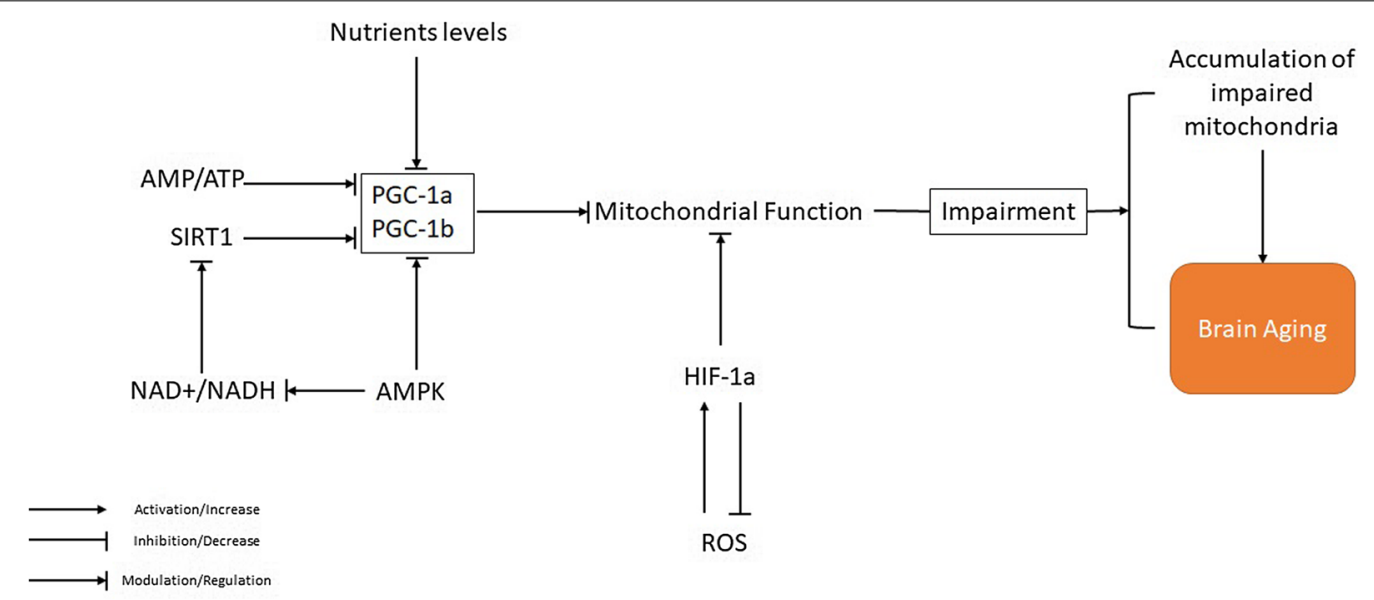

Fig. 2 Role of mitochondrial dysfunction in brain aging

impairments in mitochondrial trafficking according to their extended dimensions. Respiratory chain enzymes and mtDNA are the main targets of mitochondrial damage [119]. The mitochondrial membrane permeability transition pores (mPTP) have been known as one of the primary regulators of mitochondria during apoptosis. The MPTPs are involved in brain development and pathologically in a range of age-related neurodegenerative diseases [120].

Mitochondria extracted from the brains of different animals exhibited several age-associated changes such as mitochondrial fragmentation or enlargement [121, 122], enhanced oxidative damage to mtDNA [123, 124], enhanced amounts of mitochondria with depolarized membranes [125], dysfunction of the mitochondrial respiratory chain [126-128], impaired Ca2 + handling [127, 129], and a diminished threshold for the formation of mPTP [130].

Decrement in the function of mitochondria through brain aging associates with a decrease in the levels of intracellular NAD + and the NAD: NADH ratio, which could be assumed to endanger the activities of the NAD +-dependent enzymes that are essential for neuronal viability and function, such as Sirtuins as histone deacetylases (HDACs) that require NAD for their enzymatic activity [131, 132]. Most cell lineages in the brain probably encounter the accumulation of impaired mitochondria through aging, as proposed from investigations of astrocytes and neurons identified from brains of young and aged mice $[133,134]$.

\section{Telomere and brain aging}

Telomere shortening is one of the primary hallmarks of aging [9]. The telomere theory of aging and cellular senescence proposes that cells evaluate the number of divisions and define when replication is suitable [135]. Telomeres, also called the biological clock, consist of thousands of tandem DNA repeats, TTAGGG, at the end of each linear chromosome. The telomeres have a crucial role in genome maintenance and promote stability through replication procedure, preventing chromosomal end fusion and unnecessary recombination [136, 137]. In somatic cells, telomeres shorten gradually after each cell division [138]. Therefore, a restricted number of cellular divisions are expected, which cells lead to replicative senesce [139].

Like stem cells, telomere shortening can be reversed via the enzyme known as telomerase in some cell types. Telomerase is a ribonucleoprotein (RNP) enzyme that consists of two essential subunits: the telomerase reverse transcriptase protein (TERT) and the telomerase RNA (TER) [140]. The ability of embryonic stem cells (ESCs) and also, induced pluripotent stem cells (iPSC) to divide limitlessly is according to the up-regulation of telomerase enzyme in these cell populations [141, 142].

The role of telomere shortening and its involvement in the healthy aging procedure of the brain and neuron senescence at the cellular level is not entirely illustrated [143]. In addition, age-associated alterations, particularly in neurons, are still understudied. Because neurons are post-mitotic, cell division as the main factor for telomere erosion has been considered absent in neurons once they reach terminal replication. This opinion has been disputed by finding DNA content variations, obviously demonstrating a cell cycle activity in around $10-20 \%$ of post-mitotic neurons, as shown for the cortex of healthy aging brains and $\mathrm{AD}[144,145]$.

Studies have shown that inducing telomerase activity in somatic cells restores numerous aging features, such as senescence [146]. In somatic tissues, including the CNS, 


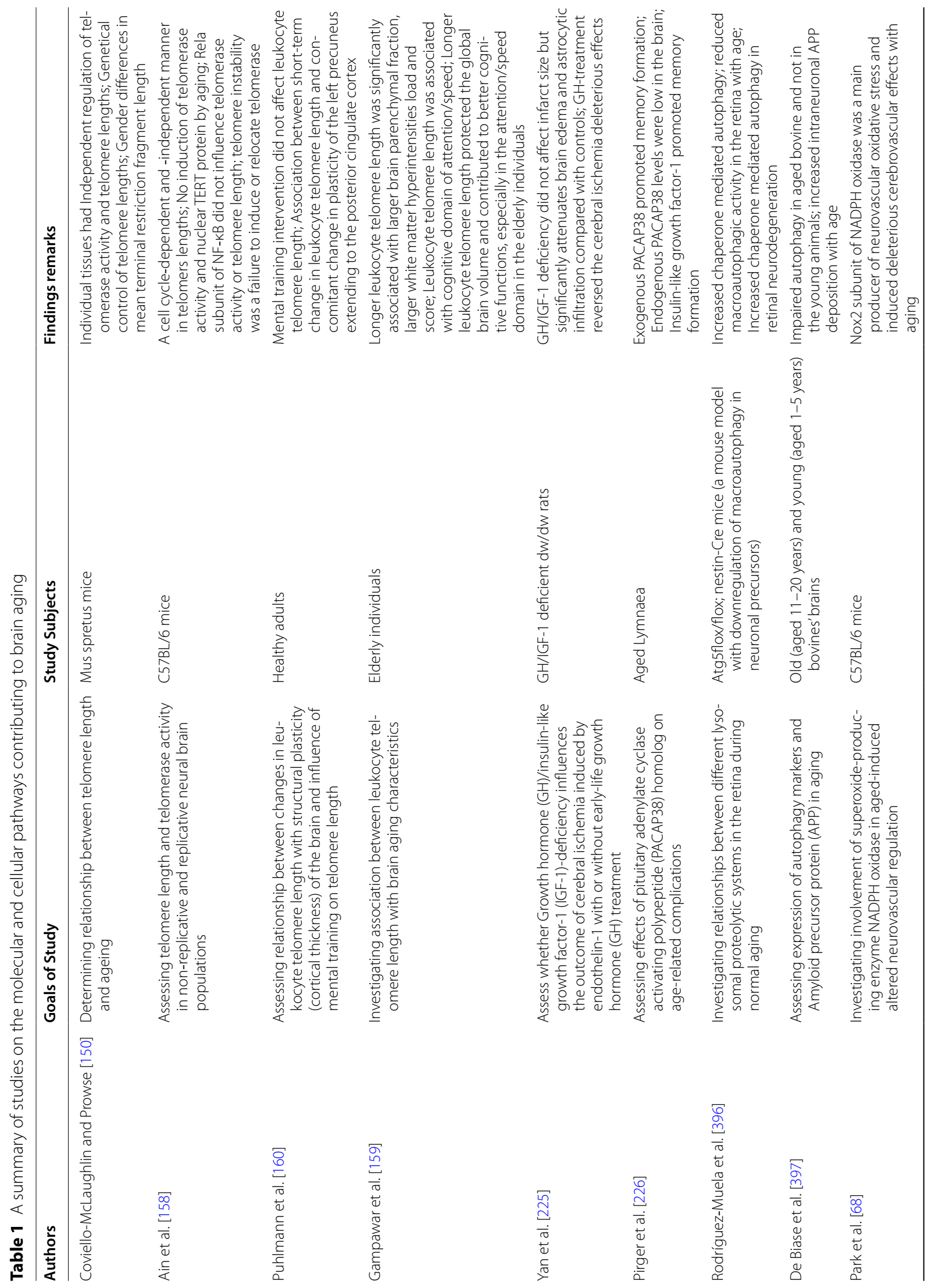




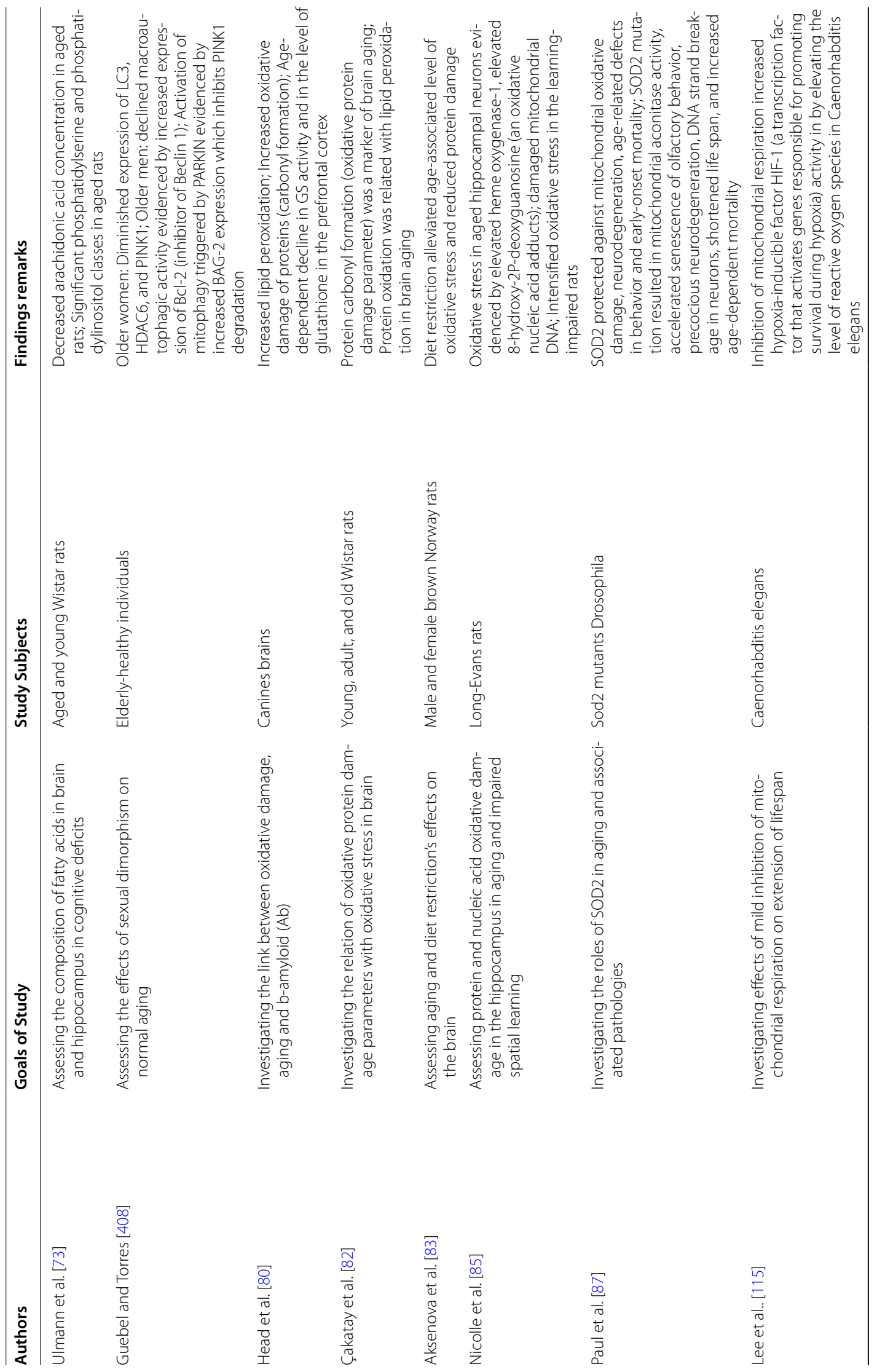




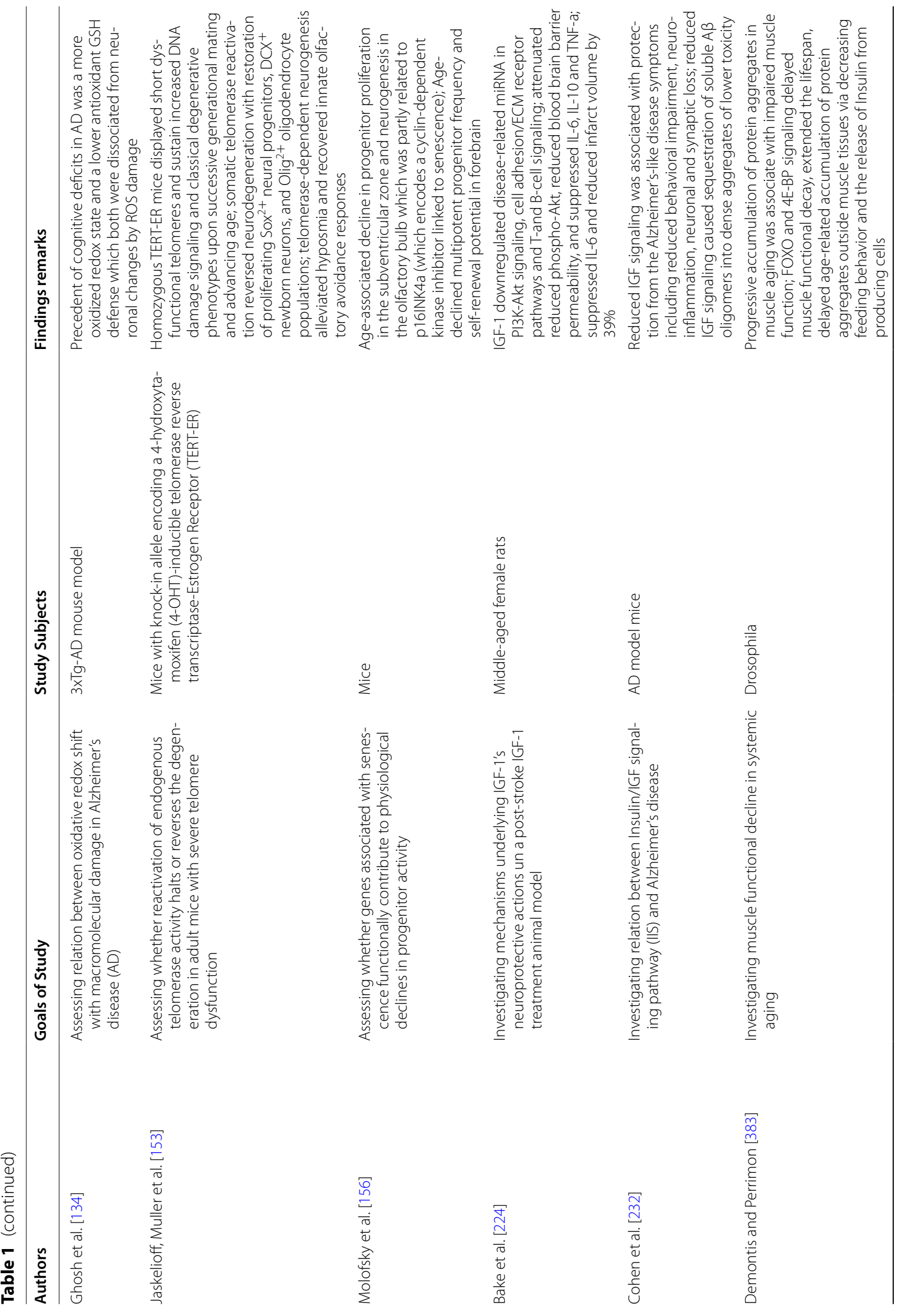


Zia et al. Behav Brain Funct $\quad$ (2021) 17:6

Page 10 of 30

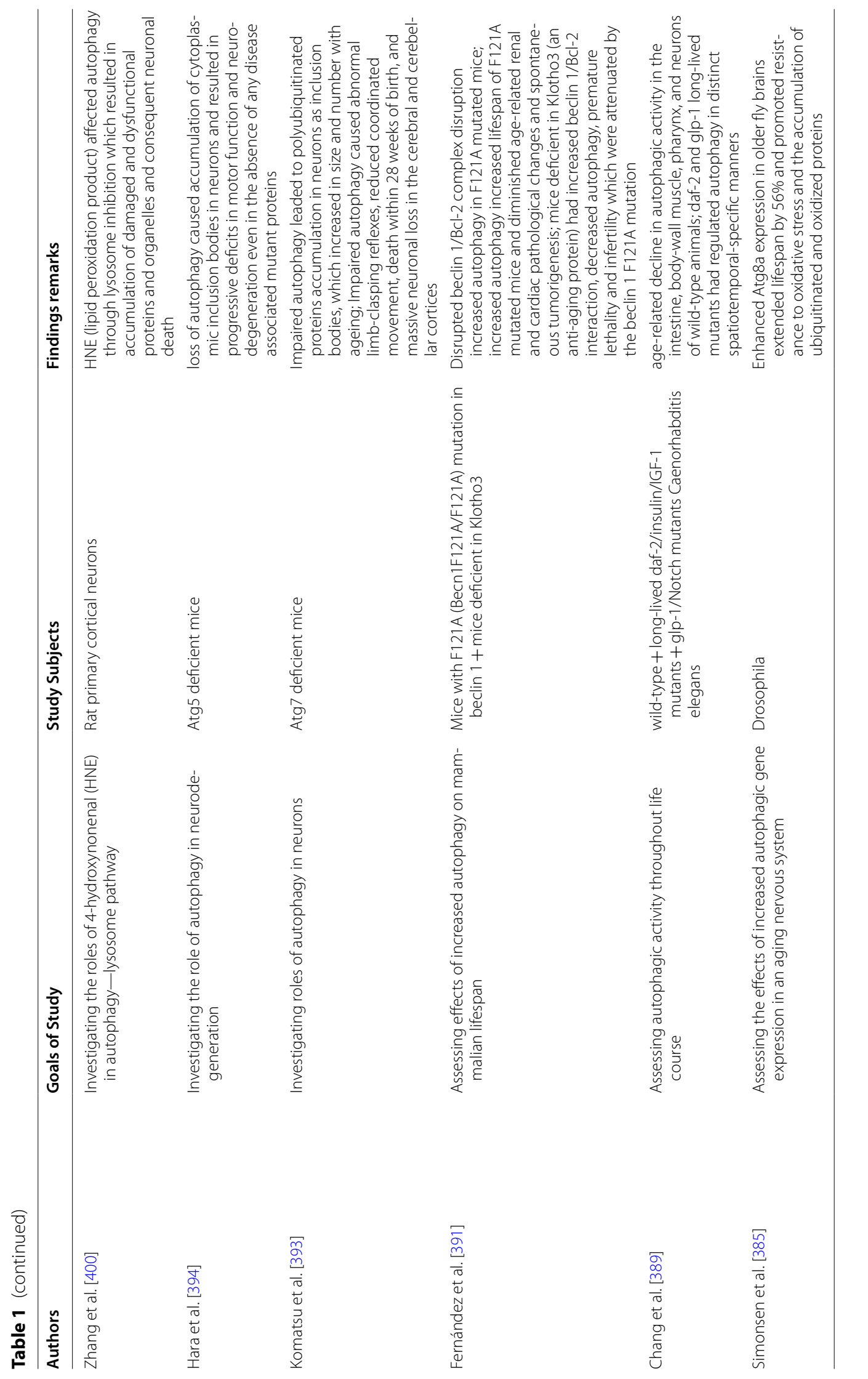


telomerase enzyme exhibits deficient transcript levels and activity, which vary in their relation with protein levels, e.g., in the murine cortex [147-149]. The telomerase function in post-mitotic cells like neurons is mainly unassociated with telomere elongation but somewhat related to cell survival-promoting function. Interestingly, Eitan et al. reported a dissociation between the decreased telomerase activity through postnatal development and the persistent levels of TERT mRNA and proteins [149]. Interestingly, in another study, Coviello-McLaughlin et al. was reported that telomeres in the brain might not pursue the telomere theory of replicative senescence and aging. They showed that in the brain of M. spretus, a mouse strain with telomeres with the same length as in humans, telomere shortening is not related to telomerase enzyme and cell turnover activity and even with the more substantial slope in comparison to other organs with limited cell turnover. This was found postnatally, whiles telomere shortening through aging was not found [150]. However, during the first few days of stem cell differentiation, the newly produced neurons are susceptible to apoptosis triggered by telomere damage [151].

Recent investigations have demonstrated that hippocampal TERT is involved in modulating mood behaviors by regulating the proliferation of neural progenitor cells (NPCs) and is required for spatial memory formation. In this regard, hippocampal-dependent learning and memory functions and neurogenesis in the hippocampus are decreased in telomerase-knockout mice [152]. In confirming, Telomerase enzyme reactivation in telomeraseknockout mice returns olfactory neurogenesis to normal status by a subsequent improvement of an olfactory dysfunction [153].

The cumulative data from more recent investigations suggest that the features of cellular senescence are not limited to replication-competent cells. In the CNS, the Post-mitotic neurons obtain a senescence-like feature due to DNA damage and telomeres dysfunction [154]. When cells go through senescence, they terminate dividing, produce pro-inflammatory cytokines, resistant to apoptosis, and express the proteins p16Ink4a and p21 [155]. The cellular senescence might be the fate of some NPCs through aging, as demonstrated by up-regulation of p16Ink4a linked with decreased amounts of proliferating NPCs in the sub-ventricular zone (SVZ) [156]. Furthermore, when human NPCs are kept in culture, they show a restricted amount of cell divisions and then go through cellular senescence [157].

Ain et al. reported that telomere attrition happens in the aging mice brain. It is not limited to neural populations with regular cell cycle activity (e.g., in glia). Ain et al. found that both cell cycle-independent and -dependent alterations in telomere length happen in the aging brain. They also provided evidence that suggests non-replicative neurons involved in the age-related telomere erosion procedure detected in the brain [158]. However, there are controversial reports describing leukocyte telomere length (LTL) associated with structural alterations to the brain and decreased cognitive capacity during aging $[159,160]$.

Structural brain indices are hallmarks of individual differences in aging and health [161]. Gampawar et al. reported a highly unique link between LTL and brain parenchymal fraction (BPF) in the elderly. Also, they found that Longer LTL is connected with a larger brain and with better cognitive functioning in the attention/ speed mediated by BPF [159]. In another study by Puhlmann et al., short-term LTL change was connected with structural brain alteration [160]. Collectively, future investigations in which senescent cells are eliminated from the aging brain of the model organisms should illustrate whether cellular senescence is a true hallmark of aging in the brain.

\section{Inflammation and brain aging}

The immune system is one of the most pivotal protective physiological systems of the organism [162]. Aging affects the function of the immune system, which is termed immunosenescence $[163,164]$. The participation of senescent cells in host immunity is associated with the release of pro-inflammatory cytokines. This phenomenon is defined as senescence-associated secretory phenotype (SASP). Given the pro-inflammatory nature of SASP, cellular senescence in different organs and tissues remarkably promotes inflammation in the elderly [165].

SASP is stimulated basically via NF- $\mathrm{kB}$ in response to oncogenic stress and DNA damage, which initiates the transcription of a host of genes including tumor necrosis factor- $\alpha$ (TNF- $\alpha$ ), interleukin-6 (IL-6), IL-8, IL-1 $\beta$ $[166,167]$. NF- $\kappa B$ is a transcription factor induced via inflammatory mediators and ROS that contributes to the deleterious and protective responses, depending on the types of induction that lead to co-activation of different cascades. NF- $\kappa \mathrm{B}$ also induces genes that regulate cellular survival, differentiation, inflammation, growth, and cell death $[168,169]$. If there is no stimulation, NF-kB is bound by the inhibitor of $\kappa B$ (ІкB), preventing nuclear translocation. Also, direct oxidation of NF- $\mathrm{kB}$ by ROS inhibits its DNA binding ability.

Moderate amounts of ROS result in the phosphorylation and degradation of $I \kappa B$, enabling the NF- $\kappa B$ activation [170, 171]. After NF-KB activation, it plays a pro-survival role via suppressing c-Jun $\mathrm{N}$-terminal kinases (JNKs) and caspase-mediated programmed cell death, up-regulating the anti-apoptotic genes and proteins involved in declining mtROS, particularly the genes, 
encoding antioxidant manganese-type superoxide dismutase (MnSOD) [172]. On the other hand, high concentrations of ROS activate Nf-kB via protein kinases. This Nf-kB activation plays a central role in stress signaling pathways including, JNK, extracellular signal regulatory kinases (ERKs), mitogen-activated protein kinase (MAPK), Src family kinases (SFK), Akt, and phosphatidylinositol-4,5 bisphosphate 3-kinase (PI3K) [173].

Similar to other organs, inflammation is a typical characteristic of brain aging [174]. It has been shown that the age-induced increase of pro-inflammatory markers (CRP, IL-6, IL-1 $\beta$, TNF- $\alpha$ ) is associated with cognitive decline $[165,175]$. A systematic review of 13 randomized clinical trials showed that doing physical exercise (aerobic and resistance) reduces inflammatory markers in healthy adults of all ages. Interestingly, older adults who performed high-intensity aerobic exercise benefited more than other ages in reduced inflammation [176]. In the same concept, a randomized study investigated the effects of aerobic, resistance, and neuromotor exercises in adults older than 60 years. It was shown that adults who performed these exercises had a significant reduction in TNF- $\alpha$ and IL- 6 , increased BDNF, and improved executive functions and attention [177]. The underlying mechanisms for the anti-inflammatory effects of physical exercise are thought to be due to the release of musclederived anti-inflammatory substances in older adults [178].

Microglia are the brain resident macrophages providing its innate immune defense. Microglia, a kind of glial cell, arise from erythro-myeloid precursors in the yolk sac, which inter the CNS during development $[179,180]$. Microglia have dual roles in the nervous system. In the healthy adult brain, microglia are ramified cells that exhibit highly motile processes, which constantly survey brain parenchyma in response to harmful agents, neuronal cell injury, or infections. By releasing trophic factors and regulator cytokines, microglia are involved in neuroprotection [181-183].

On the other hand, neuroinflammation is characterized by microglia. It is described by enhanced amounts of an intricate set of mediators, such as TNF $\alpha$, TGF $\beta$, and IL1 $\beta$, which are enhanced in elderly individuals. When neurons are damaged as a consequence of neurodegeneration or aging, microglia are activated via the production of neurotransmitters, ATP, cytokines, and ion changes in the local environment [179, 180, 184]. Links between neuroinflammatory activation of microglia and neuronal loss and decreased neurobehavioral function and cognitive impairment have been shown. Neuroinflammation causes intricate communication with oxidizing agents via redox sensors localized in receptors, transcription factors, and enzymes. These factors affect the connection between neurons and glia and neuronal function, resulting in neurodegenerative changes $[185,186]$. Also, after activation, microglial cells express a stimulable form of NOS and generate high levels of NO that lead to oxidative damage to neurons.

Furthermore, toll-like receptors (TLRs), critical for inducing innate immune responses to invading pathogen, are involved in neuroinflammation in age-associated brain diseases [187]. Hence, microglial TLR4 receptor activation can aggravate neural degeneration in models of age-associated neurodegenerative diseases. In contrast, repression of microglial activation has been defined as a therapeutic method to mitigate microglia-based neuroinflammation in cerebral ischemia [188].

Irregular activation of immune cells leads to functional impairment and degeneration of synapses in neurodegenerative diseases and brain aging; when correctly regulated, the same cascades play crucial roles in neuronal stress resistance and neuroplasticity. For instance, TNF- $\alpha$ plays a pivotal role in learning, memory, and synaptic plasticity in the hippocampus [189]. Also, TLRs play pivotal roles in innate immunity and modulating neural plasticity [187]. In mice, hippocampal neurons that are deficient in TNF- $\alpha$ receptor show enhanced susceptibility to degeneration and dysfunction in models of $\mathrm{AD}$, TBI, and epileptic seizures [190-192] and also TLRs 2 and 4 modulate energy intake and metabolism and help regulate critical aspects of the autonomic nervous system (ANS) [187].

Astrocytes might also involve in adaptive responses to age-associated neuronal stress. These cells eliminate glutamate from synapses, generate neurotrophic factors, and improve bioenergetic activity in neuronal cells. These astrocyte functions might be impaired through aging, thus aggravating pathological neuroinflammatory procedures [193-195]. The activation of NF- $\mathrm{kB}$ by TNF $\alpha$ is necessary for neuronal survival, which protects cells against $\beta$-amyloid $(A \beta)$ neurotoxicity. Further, NF- $\mathrm{kB}$ stimulates anti-apoptotic responses and maintains neurons from ischemic and excitotoxicity brain damage [196-199]. Moreover, NF-кB activation has a pivotal role in the initiation and perpetuation of inflammation via its response to $\operatorname{TNF} \alpha$ - mediated inflammatory stimuli, resulting in the stimulation of numerous chemokines and cytokines. Furthermore, NF- $\mathrm{\kappa B}$ and MAPK activation are essential in oxidative stress and $\mathrm{A} \beta$-induced neuronal cell death [200-202].

Besides NF- $\mathrm{kB}$, various transcription factors are induced via inflammatory responses, like signal transducer and activator of transcription (STAT-1) and peroxisome proliferator-activated receptor-gamma (PPAR $\gamma$ ), which also have been involved in AD (Fig. 3), [203, 204]. 


\section{Metabolic control and brain aging}

As age advances, the supply of cellular energy decreases. The responsible biochemical pathways of this decline have an essential role in longevity and healthy aging. Different evolutionary conserved signaling pathways and transcriptional modulators, like insulin/ insulin-like growth factor 1 (IGF1) signaling (IIS), the mammalian target of rapamycin complex (mTORC), AMP-activated protein kinase (AMPK), and Sirtuins pathways regulates the metabolic function during aging $[205,206]$. Also, factors like ROS and p53 signaling seem to be part of the central metabolic pathways in living cells [207, 208].

The IIS pathway is one of the well-known signaling pathways in longevity conserved from yeast to mammals [209]. The IIS pathway regulates proliferation, survival, and metabolic processes. Insulin and IGF1 bind to the insulin receptor (IR). Signaling adapter proteins, like insulin receptor substrate (IRS1-4) proteins, bind to tyrosine residues, which activate AKT and PI3K and act upon various target pathways like mTOR GSK3 $\beta$ [210, 211].

Over the last decade or more, it has been clarified that mutation in some parts of the insulin/PI3K cascade remarkably influences longevity [210, 212]. Both the cerebral vasculature and CNS are essential targets for IGF-1 and GH [213, 214]. During aging, secretion of GH and subsequently hepatic generation of IGF-1 decline remarkably. This IGF-1 decline contributes both to cerebrovascular disorders and age-associated cognitive impairment [215-217]. The available data propose that the deficiency of GH/IGF-1 promotes atherosclerosis development and also cerebral hemorrhage during aging [218-220]. The intensity of cerebral damage following acute ischemia was shown to enhance through aging, leading to deficiency of IGF-1-mediated neuroprotection [221-223]. Also, recent investigations describe that poststroke intracerebroventricular (ICV) administration of IGF-1 to aged rats remarkably declines infarct volume [224]. Yan et al. [225] reported GH/IGF-1 deficiency in the Lewis dwarf rat, as the aging model did not remarkably change the infarct size after endothelin-1-induced focal cerebral ischemia. In a study by Pilger et al. [226] in pond snail (Lymnaea stagnalis), a novel invertebrate model that was broadly used for the study of learning and memory reported that $L$. stagnalis had age-associated impairment of memory, which could be restored upon IGF-1 treatment [226]. Neuroprotective effects of IGF-1 through mammalian aging have been reported [213, 214, 227]. Likewise, IGF-1 deficiency has been engaged in the pathogenesis of several age-associated disorders and modulation of longevity in mammals [213, 214, 228]. Thus, neuroprotective and anti-aging effects of IGF-1 in L. stagnalis can be related to mammalian aging and providing more validation of the model. Low levels of IGF-1 have been found in humans who had remarkable longevity [229]. During $12 \mathrm{~h}$ of chronic restraint stress for eight weeks, mice were divided into either access to running wheels or no access. Mice with access to physical exercise by running wheels showed reduced chronic restraint stress-induced cognitive impairment and improved cell proliferation in the dentate gyrus, possibly via increase of IGF-1 and increased activity of glutathione s-transferases (GST) [230].

Some conflicts exist between the neuroprotective effects of the IIS pathway and its adverse effects on longevity. Interestingly, knockout of IRS2 receptor can decrease cognitive impairment and neurodegeneration in mouse models of $\mathrm{AD}$ [231, 232]. Furthermore, in patients with $\mathrm{AD}$, downregulation of the IIS pathway was reported [233]. Therefore, the IIS pathway as an effective neuroprotector and an indicator of the neurodegenerative procedure is disputable. IGF-1 induces an intracellular signaling cascade mediated via the PI3KAKT pathway, enabling the phosphorylation of FoxO transcription factors (Fig. 4) [234]. FOX (forkhead box) proteins regulate lifespan in some of the simple invertebrate organisms, including C. elegans [235-237]. The "O" subclass of the FOX family (FoxO) consists of evolutionarily conserved isoforms that in mammals include FoxO1, FoxO3, FoxO4, and FoxO6 C. elegans DAF-16 and DFoxO in D. melanogaster. FoxO proteins' activity is associated with different cellular processes, including cell differentiation, glucose metabolism, cellular detoxification, DNA repair, and apoptosis [235237]. The insulin/IGF-1 pathway initiates intracellular signaling mediated by AKT, enabling phosphorylation of three conserved residues within the FoxO transcription factors. The phosphorylation of FoxO by AKT results in the export of proteins to the cytosol. It suppresses FoxO-dependent genes' expression (234, 235); however, in the presence of cellular stress or the lack of growth factor signaling, FoxOs transfer into the nucleus and result in the expression of FoxO-dependent genes. Numerous mechanisms of how FoxO proteins promote the longevity of model organisms have been proposed. In model organism C. elegans, mutations in Age-1, a homolog of PI3K, extend the lifespan in model organisms. Also, mutations in Daf-2, a homolog of IR, extend lifespan in C. elegans $[238,239]$. Also, it has been reported that the loss of CHICO as an IRS homolog enhances longevity in D. melanogaster [240]. The typical role of Daf- 2 is to counteract the activity of Daf-16 as the homolog of the FoxO transcription factor. At the same time, Daf-2 mutation increases resistance to stress and lifespan via activation of Daf-16. In fact, in the $d a f-2^{-/-}$strains, AKT-1-mediated inhibition of 


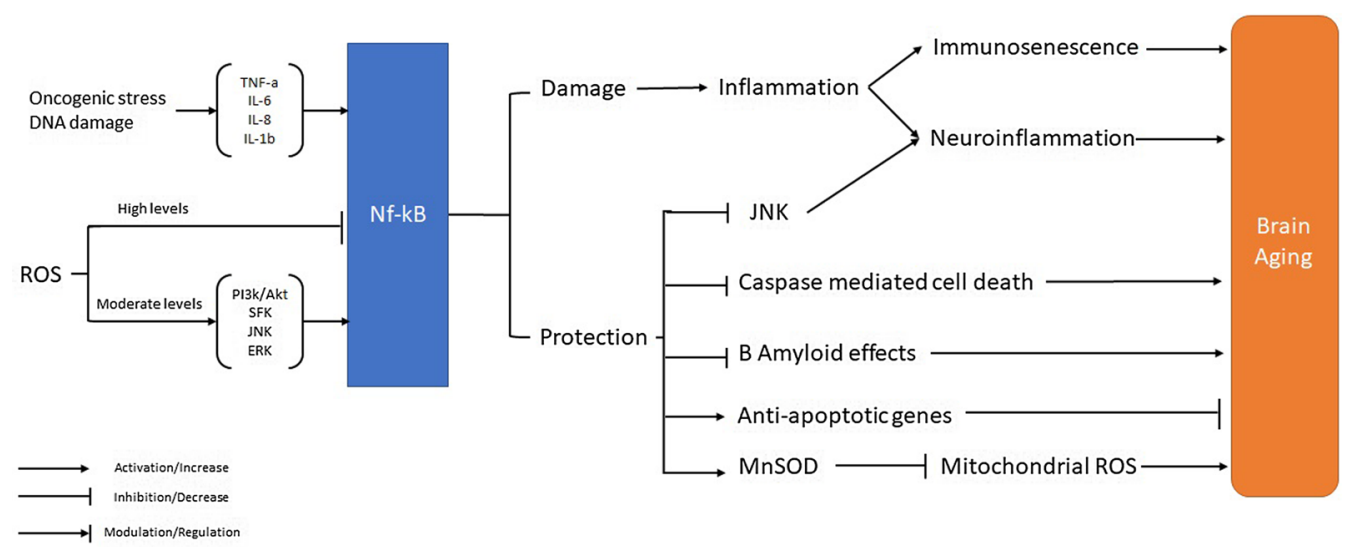

Fig. 3 Role of inflammation in brain aging

DAF-16 is down-regulated and enabling DAF-16 translocation to the nucleus to enhance the expression of target genes. Direct target genes of DAF-16/FoxO are responsible for the stress resistance and longevity phenotypes connected with daf-2/IR mutations [241, 242].

The protein kinase mTOR is a serine/threonine kinase that applies its functions as a catalytic subunit of two distinct protein complexes, mTORC1 and mTORC2 [243]. The mTOR pathway contributes to the development and aging process in living cells by regulating cellular growth and metabolic procedures in response to nutrients and nutrient-induced signals, like insulin [244]. mTOR pathway activates ribosomal protein S6 kinase (S6K), which in turn phosphorylates eukaryotic translation elongation factor 2 kinase (eEF2K) at Ser366, leading to its inhibition and thus promote dephosphorylation and activation of eEF2, which modulates gene transcription and protein synthesis $[245,246]$. The mTOR pathway is downstream of the insulin/PI3K signaling cascade and acts as the primary determinant of longevity [244]. Decreased activation of the PI3K/AKT/mTOR signaling pathways remarkably extends longevity in mice [247]. Also, centenarians that represent enhanced susceptibility to insulin have declined mTOR activity. Therefore, lifespan appears to be linked with the declined activity of the insulin/IGFinduced PI3K/AKT/mTOR signaling cascades [244, 248].

Moreover, S6K directly phosphorylates IRS proteins on multiple serine residues, consequently inhibit the insulin pathway [249]. Also, cellular exposure to compounds like rapamycin postpones cellular senescence. It decreases mitochondrial dysfunction via the inhibition of the mTOR pathway [250].

AMPK is one of the primary regulators of cellular energy levels [251]. When cellular energy levels have been compromised in mammals, this pathway is activated by increases in ADP/ATP and AMP/ ATP ratios. In this condition, the AMPK response stimulates alternative pathways that produce ATP besides inhibiting ATP consumption $[251,252]$. Therefore, AMPK activates a set of compensatory pathways, including stimulation of glucose uptake, inhibition of fatty acid synthesis, fatty acid oxidation ( $\beta$-oxidation), and enhanced mitochondrial biogenesis [253]. At the molecular level, some compounds such as metformin inhibit the mitochondrial respiratory chain in the liver and increase the levels of AMPK, which is beneficial in improving insulin sensitivity, lowering cAMP, thus reducing the expression of the gluconeogenic enzyme and also increasing physical performance and longevity [254]. Additionally, the activation of AMPK enhances longevity and is associated with metabolic improvement in mice [10]. Although, how AMPK acts on aging is very intricate and still requires more investigations to be illustrated.

The Sirtuins are evolutionarily conserved from bacteria to mammals. These protein complexes play a crucial role in regulating metabolism, insulin resistance, energy supply, oxidative stress, inflammation, neuroprotection, and longevity $[255,256]$. In mammals, there are different subtypes of Sirtuins that are located in various cellular compartments, including mitochondria (SIRT3, SIRT4, and SIRT5), cytosol (SIRT2), and nucleus (SIRT1, SIRT6, and SIRT7)[257]. The Sirtuins family of proteins is categorized as class III histone deacetylases that transfer acetyl group to ADP-ribose of $\mathrm{NAD}^{+}$generating a 2'-O-acetyl-ADP-ribose, nicotinamide, and deacetylated protein. Both SIRT1 and SIRT2 genes are up-regulated in the brain $[258,259]$. Also, SIRT1 directly interacts with the PIK3 adaptor subunit p85 and constructing a complex that, upon insulin induction, binds to IRS1/2 and stimulates this signaling cascade. Furthermore, levels of SIRT1 are associated with the phosphorylation of AKT at serine 473. Other targets of SIRT1 proteins are AMPK, 
IRS, glutamate dehydrogenase (GDH), histones, acetyl CoA synthetase, and proteins involved in regulating stress responses, metabolic pathways, and cell survival [258-260].

The p53, as tumor suppressor protein, can stimulate a series of anti-proliferative procedures, like cell cycle arrest, resulting in cellular senescence and apoptosis at the presence of cellular stress [261]. Furthermore, p53 plays an essential role in regulating and monitoring cellular energy levels and modulating some pathways like oxidative phosphorylation, glycolysis, insulin sensitivity, $\beta$-oxidation, mitochondrial integrity, and autophagy [262, 263]. Glucose transporters (GLUTs) promote glucose transport through the cellular plasma membrane, which is the first rate-determining stage in glucose metabolism. Experiments have been shown that p53 directly inhibits glycolysis via suppressing the transcription of GLUT1 and GLUT4 to decrease glucose uptake [263, 264]. p53 also indirectly suppresses GLUT3 expression via down-regulation of the activity of NF- $\mathrm{kB}$, which upregulates the transcription of GLUT3 in the cells. p53 also prevents the GLUT1 translocation to the plasma membrane to inhibit glucose uptake. One of the primary mechanisms by which p53 prevents the translocation of GLUT1 to the plasma membrane is via up-regulation of its target RRAD, which binds to p65 of the NF- $\mathrm{kB}$ and prevents NF- $\mathrm{kB}$ activity from inhibiting GLUT1 translocation [264, 265]. p53 regulates a broad spectrum of proteins involved in glycolysis, acting as a modulator of glycolytic activity [266, 267]. Moreover, p53 promotes oxidative phosphorylation via transcriptionally increases the cytochrome c oxidase assembly two protein (SCO2) expression, which is required for the assembly of the catalytic core of cytochrome c oxidase (COX) and apoptosis-inducing factor (AIF). p53 suppresses the transcription of pyruvate dehydrogenase kinase-2 (PDK2), which is a negative modulator of pyruvate dehydrogenase $(\mathrm{PDH})$. This enhances the conversion of pyruvate into acetyl-CoA for entry into the tricarboxylic acid (TCA) cycle, which positively modulates glucose oxidation. p53 also stimulates the Parkin (PARK2) expression, a component of an E3 ubiquitin ligase complex and modulator of antioxidant defense and energy metabolism [268, 269]. Therefore, p53 protein modulates aging acts via linking the cellular energy supply with the stage of senescence progression (Fig. 5) [270, 271].

AKT is involved in many physiological processes in the central and peripheral nervous system, including the regulation of neuron survival [272]. Also, the PI3KAKT signaling pathway is a critical modulatory step in the response of the cells to oxidative stress. During brain development, the PI3K pathway is involved in various cellular functions, such as cell migration, proliferation, and axon guidance [273]. Furthermore, the activity of PI3K is necessary for the transport of microtubule during neuronal polarization as well as neuronal growth and formation [274]. Also, PI3K/Akt pathway through cAMP-response element-binding (CREB) protein induces fibroblast growth factor 2 (FGF2) and activates FGF receptor 1 (FGFR1). PI3K/Akt modulates neural hippocampal progenitor proliferation and differentiation through FGF2 and FGFR1 [275].

CREB is a cellular transcription factor that modulates the expression of essential genes in dopaminergic neurons and molecules essential for long-term memory and neuronal plasticity [276, 277]. Dopamine acts exclusively through G-protein-coupled receptors (GPCRs), which affects the phosphorylation of CREB via its GPCRs [278]. Brain-derived neurotrophic factor (BDNF) is highly conserved in gene function and structure through vertebrates between the different neurotrophins. It serves as a significant regulator during brain development synaptic plasticity. The CREB plays a crucial role in mediating neurotrophin responses in neurons since the exposure of neurons to BDNF induces CREB phosphorylation and activation, which acts as an essential regulator of BDNF-induced gene expression (279). Also, it has been found that the CREB itself can be regulated

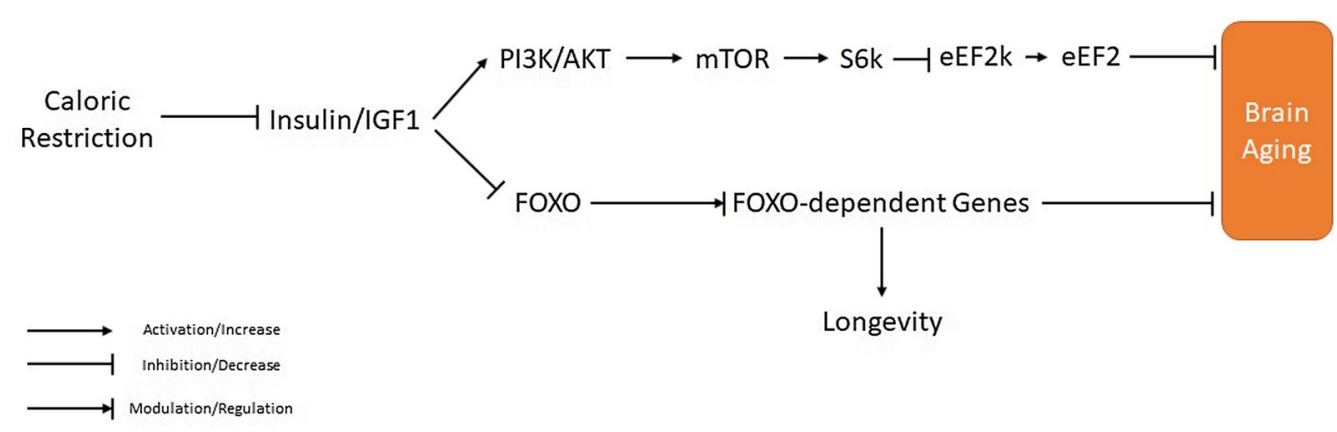

Fig. 4 Molecular pathway involved in caloric restriction effect on brain aging 
by BDNF $[276,279]$. Animal studies have shown a positive association between CREB mRNA and BDNF with memory improvements[280].

One of the growth factors contributing to the beneficial effects of physical exercise is BDNF.

Animal studies have shown that voluntary exercise increases BNDF expression and production in the hippocampus, cerebellum, and frontal cortex. Inhibition of BDNF activity suppressed the physical exercise-induced improvement of cognitive test performance [281]. It has been shown that BDNF availability has a direct correlation with cell proliferation in the hippocampus [281]. BDNF also affects neurotransmitter release and synaptic plasticity [282, 283]. Furthermore, the effect of physical exercise on neurotransmitters can be through BDNF as it regulates neurotransmitters, including dopaminergic and cholinergic systems. It has been shown that reduced intrinsic availability of BDNF by gene deletion or inhibition impairs LTP [284, 285]. Accordingly, abolishing BDNF by exogenous administration restored the ability to induce LTP in the hippocampus [286].

It was shown that following a 3-week running period, mice had elevated BDNF levels compared with sedentarism. Elevated BDNF levels persisted until two weeks after the running period. However, BDNF levels returned to pre-exercise levels three weeks after the running period. Furthermore, elevated BDNF levels were correlated with cognitive improvement in the radial water maze [287]. In the same context, it was shown that aerobic physical exercise in non-demented sedentary older adults aged between 55 and 80 years was associated with gained volume in the anterior hippocampus and improved spatial memory. Also, an increase in levels of BDNF was seen with the gain of volume in the anterior hippocampus [39]. Accordingly, clinical studies have shown that some specific polymorphisms in the BDNF gene can induce learning impairments in individuals [288]. Clinical studies have shown that physical exercise affects BDNF production in brain regions responsible for the cognitive activity, such as the hippocampus and caudal cortex [289]. Overall, these findings show that physical exercise can protect against age-induced impairments in cognitive activity by regulating BDNF. In the concept of $A D$, it has been shown that animal models of AD have BNDF deficits which can be upregulated by physical exercise and an enriched environment [290-292].

In contrast, in an $\mathrm{AD}$ transgenic mice model, physical exercise was associated with decreased BDNF. The possible explanation for these conflicting findings is not comparable to AD animal models and types of physical exercise. Various mechanisms have been suggested for physical exercise-induction of BDNF activity in the brain, including neurotransmitters with their receptors and peripheral factors such as estrogen, corticosterone, and possibly insulin-like growth factor 1 (IGF-1) [40, 41, 293-297]. Physical exercise can affect neurogenesis by regulating the systemic production of IGF-1. It was reported that physical exercise-induced neurogenesis was abolished by blocking the entrance of IGF- 1 to the brain [293]. In addition, IGF-1 facilitates the physical exercise induction of angiogenesis as systemic administration of IGF-1 increased angiogenesis. Its inhibition reduced the formation of new blood vessels in the brain of animals. The underlying mechanisms for IGF-1-induced angiogenesis are thought to be through induction of VEGF by IGF-1. Accordingly, it was shown that IGF-1 suppression reduced the secretion of VEGF and hence the formation of new capillaries [298]. Studies have shown that physical exercise increases the levels of IGF-1 and VEGF both in young and old aged individuals [299]. Also, IGF-1 acts as an upstream regulator of BDNF expression as peripheral IGF-1 administration increases the BDNF expression in the brain [293, 295, 300]. Physical exercise was shown to increase acetylcholine (Ach) levels and muscarinic receptor expression in the hippocampus of adult rats [297]. Studies have shown that physical exercise can regulate BDNF expression in the hippocampus through direct modulation of Ach [294, 301]. In confirmation, recombinant human BDNF induced the activity of basal forebrain cholinergic neurons and dopamine uptake in vitro [302].

Studies have shown that environmental enrichment increases BDNF levels, especially in the hippocampus [303]. Similarly, a fivefold increase in BDNF levels was found after one year of environmental enrichment [304]. In confirmation, BDNF deletion led to impairments in LTP and synaptogenesis following mental activity [286, 305]. In an animal model of Huntington's disease, BDNF levels were increased in the striatum following exposure to environmental enrichment. Moreover, animals showed improved survival and motor functions [306].

Also, CREB is one of the primary mediators of the PI3K/Akt pathway. There is likely crosstalk among Akt/ CREB pathway and susceptibility genes [307]. Moreover, Early investigations have shown that up-regulation of $\mathrm{AKT}$ in neurons inhibits apoptosis through growth factor withdrawal [308]. AKT1 and AKT2 expression in CNS are enhanced in the early steps of embryonic development but decline gradually in post-natal cells [309]. In the adult brain, the AKT1 and AKT2 expression are weak.

In contrast, a significant enhancement in the AKT1 expression is stimulated when cells are exposed to a harmful stimulus [310, 311]]. The expression of AKT has demonstrated to be essential and adequate for the survival of neurons, as a dominant-negative mutant 

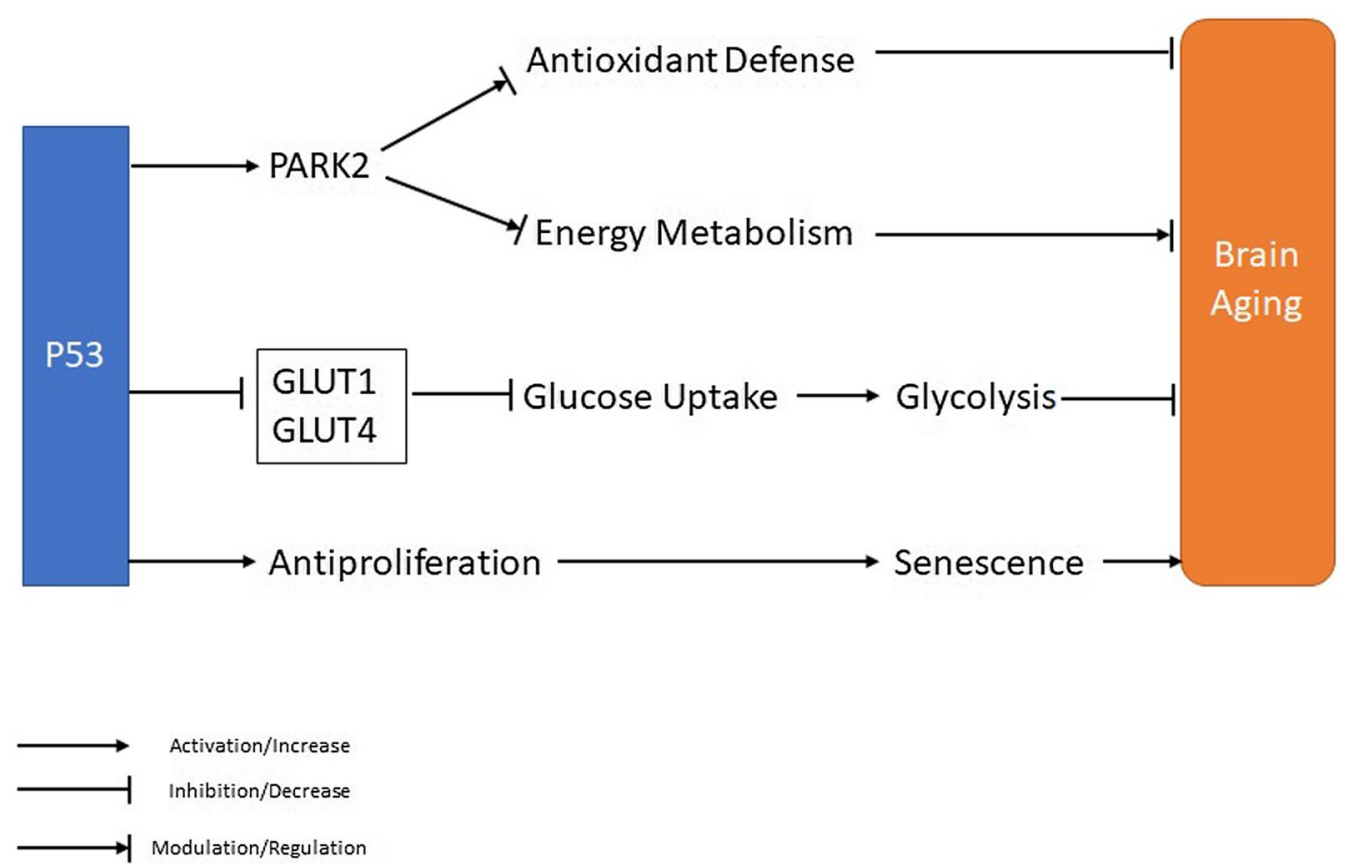

Fig. 5 Role of p53 protein acts on the cellular energy supply during the process of aging

of AKT, or the suppression of PI3K, that result in programmed cell death of neurons even in the presence of neurotrophic factors and stimulates apoptosis through oxidative stress [312, 313]. Moreover, investigations have shown that intracellular AKT protects cells against damage. In different paradigms of neuroprotection, phosphorylation of AKT modulates neuronal survival elicited by antioxidants [312-314].

It has been shown that physical exercise enhances adult neurogenesis in the dentate gyrus and increases synaptic plasticity. In this regard, the PI3K activation promotes the survival of adult-born neurons in the dentate gyrus granule cells produced through physical exercise, which consequently enhance synaptic plasticity [315].

The PI3K/AKT signaling pathway has an essential role in synaptic plasticity, learning, and memory procedure in the brain. PI3K/Akt pathway is involved in the maintenance and induction of long-term potentiation (LTP) in the hippocampal CA1 region of adult brains [316]. The PI3K/Akt pathway has been proposed for LTP at the perforant path-granule cell synapses. ICV infusions of LY294002 as an inhibitor of PI3K pathway impaired maintenance of LTP in the hippocampus and are linked with phosphorylation of AKT at Ser473 [317]. Furthermore, PI3K/Akt pathway has been reported to be needed for amygdala fear conditioning [318]. Accordingly, after infusion of the LY294002 together with wortmannin as inhibitors of PI3K and also rapamycin as an inhibitor of mTOR pathway, into the medial prefrontal cortex
(mPFC) impaired the long-term retention of trace fear memories [274].

The PI3K-Akt pathway is also required for the receptor trafficking at the synaptic membrane, affecting synaptic plasticity as part of neuronal function and development in the CNS $[319,320]$. AKT pathway is also implicated in the regulation of synaptic strength through GABA receptor phosphorylation. Moreover, the induction of insulin stimulates the PI3K activation at dendritic synapses, which then stimulates AKT activation in the post-synaptic space [321].

It has been shown that exposure to BDNF or neurotrophin 3 (NT-3) promote maturation of developing neuromuscular synapses, also axonal and dendritic sprouting, and alterations in the number of synapses in hippocampal neurons, which PI3K pathway promotes long-lasting synaptic plasticity that depends on levels of protein synthesis in both pre-and post-synaptic vicinities mediated through the induction of the eukaryotic translation initiation factor-alpha (eIF2- $\alpha$ ), that is the main target of mTOR pathway [322, 323]. Also, oxidative stress linked with elevated cholesterol uptake impairs insulin signaling, enhances serine phosphorylation of IRS1, and inhibits insulin-induced PI3K and AKT activities, resulting in enhanced stress-induced JNK activity that increases cognitive impairments in mice [324].

Observational, preclinical, and clinical trials provide evidence that $C R$ can increase the lifespan by $1-5$ years while improving health and quality of life [325]. CR 
modulates the intrinsic processes of aging by adapting the cellular and metabolic mechanisms. The mild cellular stress following CR stimulates the survival-promoting mechanisms [326, 327]. This has been shown as CR exhibited protection against brain aging and neurodegeneration by increased neurotrophic factors, particularly BDNF and GDNF [328-333].

Another element of the survival mechanisms induced by $C R$ against aging is chaperone proteins. Chaperone proteins promote the correct folding of functional proteins and eliminate non-specific aggregation of nonnative proteins. Chaperons also regulate apoptosis by modulating apoptosis inducers such as caspases [334336]. It has been shown that CR protects against neurodegeneration by increasing the HSP family of chaperons, especially heat-shock protein-70 (HSP-70) and glucoseregulated protein 78 (GRP-78), in several brain regions of aging rodents [337-341]. It has been suggested that CR causes neuroprotection by both limiting the inflammatory response of microglial cells and also stimulating the neuroprotective phenotype of microglia by inducing the production of interferon- $\gamma$ (INF- $\gamma$ ) [342, 343]. Calorie restriction reduced insulin and glucose levels while increasing glucose and insulin sensitivity in rodents and monkeys [344-347].

Furthermore, calorie restriction increased glucose utilization in rats by suppressing TNF- $\alpha$ mediated insulin resistance through negative regulation of NF- $\mathrm{KB}$ [348, 349]. CR decreases insulin and IGF-1 levels in plasma, resulting in decreased PI3K/Akt pathway activity. Decreased activity of PI3K/Akt reduces the phosphorylation of FoxO transcription factors. Thus the translocation of FoxO from the nucleus decreases. This results in decreased cytoplasmic FoxO levels and increased expression of FoxO factors. Consequently, the expression of FoxO regulated genes increases [350-353]. According to lifespan increasing effects of $\mathrm{CR}$, increased expression of FoxO factors has positive correlations with increased lifespan in worms and flies [354, 355].

Peroxisome proliferator-activated receptors (PPARs) and their co-factors as PPAR coactivator 1 (PGC-1) regulate genes involved in response to stressful stimuli regarding nutrients and their metabolism [349]. Expression of PPARs has been shown to decrease in aging and be counteracted by CR in primates [356, 357].

Limited food sources upregulate the homolog of the Sirtuins family of proteins in yeast named the silent information regulator 2 (SIR2). SIR2 gene was first found in the yeast and acted as the silencer of the extra copies of mating-type information [358, 359]. SIR2 overexpression prolonged lifespan in yeast, worms, and flies[360-362] and shortened lifespan when inactivated [363]. It has been shown that in the brain of mice exposed to calorie restriction, SIRT1 (the mammalian ortholog of SIR2) and NAD levels are increased [364]. In line with this, SIRT1 overexpression decreased the $A \beta$ peptide by increasing the cleavage of amyloid precursor through $\alpha$-secretase in primary neuronal cultures [364]. Also, some studies have shown that SIRT1 may decrease the toxicity of $A \beta$ by modulating the activity of the NF- $\mathrm{KB}$ transcription factor $[365,366]$. Furthermore, SIRT1 homolog, SIR2, has shown neuroprotective effects against Huntington's disease by recovering dysfunctional neuronal phenotype in a nematode model of the disease [367]. Taken together, CR has shown protection against brain aging and neurodegenerative diseases by modulating BDNF and GDNF, HSP family of chaperon proteins, microglial cell activity, insulin and glucose pathway, FoxO transcription factors, PPARs family of nuclear hormone receptors and, Sirtuins family of proteins.

\section{Autophagy and brain aging}

Autophagy or "self-eating" relates to the degradation procedure of damaged organelles, protein aggregates, and toxic substances that are entrapped within the lysosome [368]. Autophagy is necessary to maintain cellular homeostasis and integrity by providing metabolites needed to survive cells under extreme stress conditions [369]. Furthermore, autophagy can help maintain cellular energy status through nutrient restrictions during the catabolic pathway, which functions as a fueling and recycling procedure to provide vital energy and building blocks for the synthesis of the macromolecules [370]. There are different kinds of autophagy: microautophagy, macroautophagy, and chaperone-mediated autophagy (CMA). All of these are various in their functions and mechanisms of action [371]. Microautophagy is the non-selective lysosomal degradative procedure, which includes direct engulfment of cytosolic cargo at a boundary membrane via autophagic tubes, which mediate invagination of vacuolar membrane and scission of vesicle into the lumen [372]. Macroautophagy, commonly known as autophagy, needs to form a double-membrane structure called the autophagosome, which enclose cellular material and later fuse with the lysosomes [373]. CMA ensures the selective degradation of cytosolic proteins. Substrate proteins bind to the lysosomal membrane through the specific receptor called lysosome-associated membrane protein type $2 \mathrm{~A}$ (LAMP-2A) [374].

Between the different signaling networks modulating autophagy, two kinases are associated with lifespan and aging regulation, including mTOR and AMPK [375]. mTOR, a negative modulator of autophagy, combines signals from growth factors and nutrient pathways to regulate cellular metabolism and growth [376]. Under nutrient-rich growth conditions, mTOR inhibits 
autophagy via direct phosphorylation of unc-51-like autophagy, activating kinase 1 (ULK1) and ATG13, which sequesters the ULK1 complex in an inactive state. Conversely, extreme stress conditions, like nutrient deficiency, inhibit the mTOR pathway and enhance autophagy [377]. However, in nutrient-deficient conditions, AMPK is activated and promotes autophagy by activating ULK1 via direct phosphorylation of Ser 317 and Ser 777. Also, AMPK stimulates autophagy by inhibiting the mTOR pathway via phosphorylating Raptor. This adaptor protein is essential for mTOR kinase activity. Ultimately, AMPK induces tuberous sclerosis complex 1/2 (TSC 1/2), inhibiting mTOR [375, 377, 378].

Autophagy can maintain cellular homeostasis when faced with different stress during aging, such as growth factor withdrawal, nutrient deprivation, damaged proteins and organelles, and genotoxic stress [379]. The recycling functions of autophagy reduce these stresses by removing impaired organelles and other damaged cellular components. Therefore, stress-mediated autophagy is part of a broader metabolic shift that promotes cells and organisms' survival by prioritizing maintenance and repair overgrowth [380]. Aging is associated with decreased autophagy in different model organisms. Early investigations exhibited that aged rats, C.elegans, and human cells have diminished lysosomal degradation compared to younger counterparts [381, 382]. Also, aging is associated with the down-regulation of numerous ATGs in D. melanogaster and rodent tissues [383-385]. In humans, the expression of ATG5, ATG7, and BECN1 is decreased through normal aging. At the same time, age-related disorders like osteoarthritis, cardiomyopathy, and neurodegeneration show declined autophagy [386-388]. Recent work in C. elegans establishes a significant decrease in autophagic flux in vivo through the lifetime, noted by an age-related aggregation of immature autophagosomes and diminished autophagic degradation in all tissues examined [389]. Moreover, the aggregation of unremoved autophagosomes through aging might worsen neuronal dysfunction in age-associated disorders in worms [390]. In mice, an age-related decline in the amounts of autophagosome has been found, as may be anticipated by the age-associated decrease in ATG expression in humans [391].

Because neurons are usually considered post-mitotic cells and must protect their intricate function and structure integrated into neuronal networks during the organism's lifespan, the capability to eliminate dysfunctional and damaged molecules and organelles is an essential function survival of neurons. Saha et al. reported an agerelated lack of macroautophagy function in dopaminergic neurons in the C. elegans model organisms [392]. Also, deletion of the Atg7 gene in mice results in neuronal loss and death within 28 weeks [393]. similarly, the absence of the Atg5 gene causes progressive deficits in motor function that are in line with the accumulation of cytoplasmic inclusion bodies in the mouse brain [394]. Further, amounts of Beclin 1 in the brain were reported to be decreased in old naked mole-rats, proposing an agerelated decline in macroautophagy in this species [395]. Also, Rodríguez-Muela et al. [396] investigated ageassociated alterations in autophagic mechanisms in the mouse retina. They reported lower Beclin 1 and LC3-II after the lysosomal blockage in older mice. However, De Biase et al. [397] reported lower Beclin 1, but an enhance in the LC3-II/LC3-I ratio in old cow brain specimens.

Lysosome $\mathrm{pH}$ gradients are primarily maintained via the plasma membrane V-ATPase, which pumps protons into the lysosomal lumen by consuming ATP [398]. Impairment of V-ATPase influences lysosomal acidification, which disturbs the removal of substrates and results in various diseases, such as neurodegenerative disorders [399]. Also, HNE can impair the function of lysosomes in cerebral cortical neurons that leads to the accumulation of cargos that are not degraded and consequent cell death [400]. Furthermore, the most remarkable morphologic alteration in neurons through normal aging is the accumulation of autophagic vacuoles filled with lipofuscin or neuromelanin pigments [401].

Autophagy plays a substantial role in removing damaged mitochondria which are known as mitophagy [402]. The accumulation of damaged and dysfunctional mitochondria in dopaminergic neurons is characteristic of PD. Also, defective mitophagy contributes to mitochondrial dysfunction in PD [403]. PINK1 and Parkin have been involved in suppressing inflammatory responses triggered via mitochondrial dysfunction, which leads to the loss of dopaminergic neurons in PD [404, 405]. Although knockout of Pink1 and Prkn in mice failed to promote PD-related phenotypes, and similarly in mice and D. melanogaster, Pink1/Parkin was not essential for mitophagy. These findings suggest that other factors modulate mitophagy and PD [406, 407].

Guebel and Torres

[408] investigated the effects of gender and aging on gene expression in the hippocampus. They reported diminished expression of LC3, HDAC6, and PINK1 in older women. Enhanced expression of Bcl-2, an inhibitor of Beclin 1, in older men proposed a decline in macroautophagy activity. Inversely, enhanced expression of BAG-2 expression, which inhibits PINK1 degradation via suppressing its ubiquitination and triggers PARKINinduced mitophagy, in older men proposed activation of mitophagy. These investigations emphasize the intricate role of autophagy in the homeostasis of mitochondria. Also, there is a need for more investigation to reveal how 


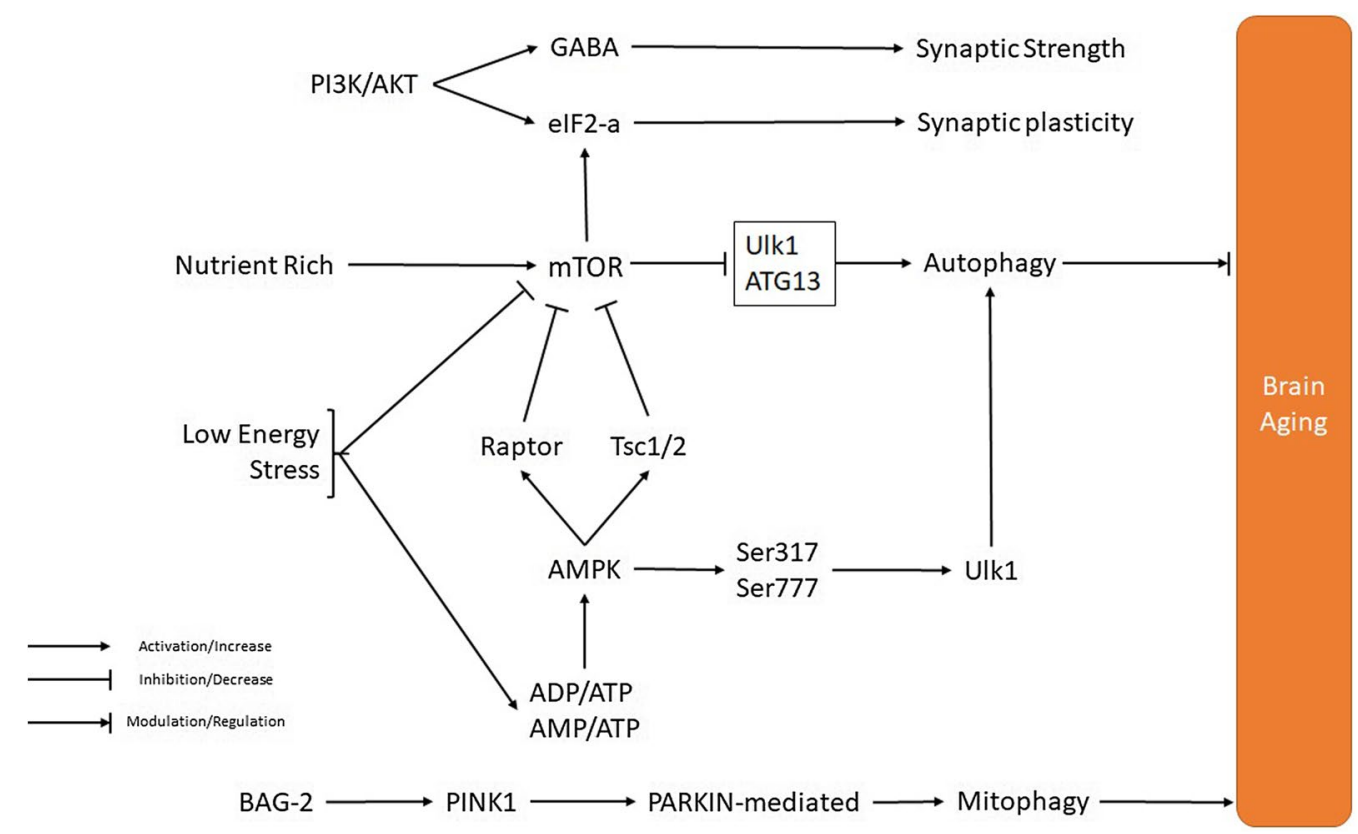

Fig. 6 Role of autophagy pathway in brain aging

mitophagy acts to prevent age-associated neurodegeneration. Thus, autophagy appears to be a compensatory response to cellular metabolic status, either to acquire energy or to remove impaired mitochondria. Finding the interrelationship between both modulators is necessary to link the energetic signaling to metabolism. Figure 6 indicates an association between the autophagy pathway and brain aging.

\section{Conclusion}

Aging is an intricate and multifaceted biological procedure that includes all organ systems. Cellular dysfunction and accumulation of senescent cells are frequent in the central part of them. As well as, investigation in the areas of aging and neurobiology has demonstrated various factors during brain aging at the molecular, cellular, and tissue levels. Aging is the leading risk factor for a broad range of neurodegenerative disorders. Brain diseases of aging have recently become the main reasons for disability and death, according to advances in the treatment and prevention of some challenging diseases such as cardiovascular disease and cancers, which have enabled more people to live over 70 . Gene expression profiling and brain imaging techniques provide a powerful tool to identify global alterations at the molecular, cellular, and behavioral statuses in aging brains. After having an overview of the recent developments on brain aging, in the present review, it has been described as the result of declined neurogenesis and synaptic plasticity, altered neurochemical and signaling pathways, including increased oxidative stress, impaired mitochondrial function, glial cell activation, impaired protein processing, and neuroinflammation.

Moreover, the neocortex and hippocampus are the most vulnerable areas, affected in aging with a variable degree of molecular and cellular alterations in their sub-centers. Although each of these age-associated alterations is common in the process of normal aging, their combined influence, together with the genetic background and environmental conditions, could trigger the solemn circle of cytotoxic activation. These alterations are associated with transcription factors, proteins, and environmental factors within the cell, like redox potential. Although, the main factor regulating the whole procedure remains uncertain. One of the first candidates would be to find how the redox capacity defines gene transcription and promotes responses in metabolism during brain aging.

Moreover, animal models have demonstrated that metabolic control and calorie restriction (CR) can significantly affect brain aging and susceptibility to neurodegenerative disorders. Recent findings suggest that calorie restriction and physical exercise increase neuroplasticity and resistance of the brain to stress and aging. Finding the cross-talk between the main pathways and their genetic and environmental regulation will be the main challenge in brain aging and neurodegenerative diseases. 
Our understanding of brain aging is still at the beginning. More investigation is needed to establish effective therapeutic methods and drug development against brain aging. Furthermore, non-pharmacological methods, such as physical exercise, lifestyle changes, and calorie restriction, could enhance healthy aging via their effects on promoting the brain's physiological functions while decreasing ROS production and inflammation. Understanding the mechanisms that underlie the hallmarks will be essential to designing future interventions to halt or even reverse brain aging. Collectively, the primary purpose of investigation in neurobiology and brain aging should be to determine methods and strategies to promote successful brain aging in all people.

\section{Acknowledgements}

Not applicable.

\section{Authors' contributions}

SS and AZ Acquisition of data: AZ and TF. Drafting of the manuscript: SS, AZ. TF, and AP. Critical revision: SS. All authors read and approved the final manuscript.

\section{Funding}

Not applicable.

\section{Availability of data and materials}

The data that support the findings of this study are available in the body of the text.

\section{Declarations}

Ethics approval and consent to participate

Not applicable.

\section{Consent for publication}

Not applicable.

\section{Competing interests}

There is no conflict of interest.

\section{Author details}

${ }^{1}$ Department of Biochemistry, Institute of Biochemistry and Biophysics (IBB), University of Tehran, Tehran, Iran. ${ }^{2}$ Medical Toxicology and Drug Abuse Research Center (MTDRC), Birjand University of Medical Sciences (BUMS), 9717853577 Birjand, Iran. ${ }^{3}$ Cardiovascular Diseases Research Center, Birjand University of Medical Sciences, Birjand, Iran. ${ }^{4}$ Faculty of Pharmacy, Birjand University of Medical Sciences, Birjand, Iran. ${ }^{5}$ Noncommunicable Diseases Research Center, Neyshabur University of Medical Sciences, Neyshabur, Iran.

Received: 28 January 2021 Accepted: 27 May 2021

Published online: 12 June 2021

\section{References}

1. Coffey CE, Lucke JF, Saxton JA, Ratcliff G, Unitas LJ, Billig B, et al. Sex differences in brain aging: a quantitative magnetic resonance imaging study. Arch Neurol. 1998;55(2):169-79.

2. Tosato M, Zamboni V, Ferrini A, Cesari M. The aging process and potential interventions to extend life expectancy. Clin Interv Aging. 2007:2(3):401

3. Kiss H, Mihalik Á, Nánási T, Őry B, Spiró Z, Sőti C, et al. Ageing as a price of cooperation and complexity: self-organization of complex systems causes the ageing of constituent networks. Nat Prec. 2008;21:1-16.
4. Floyd RA, Hensley K. Oxidative stress in brain aging: implications for therapeutics of neurodegenerative diseases. Neurobiol Aging. 2002;23(5):795-807.

5. Mariani E, Polidori MC, Cherubini A, Mecocci P. Oxidative stress in brain aging, neurodegenerative and vascular diseases: an overview. J Chromatogr B. 2005;827(1):65-75.

6. Samarghandian S, Azimi-Nezhad M, Farkhondeh T. Thymoquinoneinduced antitumor and apoptosis in human lung adenocarcinoma cells. J Cell Physiol. 2019;234(7):10421-31. https://doi.org/10.1002/jcp. 27710.

7. Huffman KJ. The developing, aging neocortex: how genetics and epigenetics influence early developmental patterning and age-related change. Front Genet. 2012;3:212.

8. Wanagat J, Allison DB, Weindruch R. Caloric intake and aging: mechanisms in rodents and a study in nonhuman primates. Toxicol Sci. 1999;52(1):35-40.

9. López-Otín C, Blasco MA, Partridge L, Serrano M, Kroemer G. The hallmarks of aging. Cell. 2013;153(6):1194-217.

10. Riera CE, Merkwirth C, De Magalhaes Filho CD, Dillin A. Signaling networks determining life span. Annu Rev Biochem. 2016;85:35-64.

11. Gui XUE, Chuansheng C, Zhong-Lin LU, Qi D. Brain imaging techniques and their applications in decision-making research. Xin li xue bao Acta psychologica Sinica. 2010;42(1):120.

12. Duan W, Guo Z, Jiang H, Ware M, Li X-J, Mattson MP. Dietary restriction normalizes glucose metabolism and BDNF levels, slows disease progression, and increases survival in huntingtin mutant mice. Proc Natl Acad Sci. 2003:100(5):2911-6.

13. Willette AA, Bendlin BB, McLaren DG, Canu E, Kastman EK, Kosmatka KJ, et al. Age-related changes in neural volume and microstructure associated with interleukin-6 are ameliorated by a calorie-restricted diet in old rhesus monkeys. Neuroimage. 2010;51(3):987-94.

14. Bales CW, Kraus WE. Caloric restriction: implications for human cardiometabolic health. J Cardiopulm Rehabil Prev. 2013;33:4.

15. Han X, Ren J. Caloric restriction and heart function: is there a sensible link? Acta Pharmacol Sin. 2010;31(9):1111-7.

16. McCay CM, Crowell MF, Maynard LA. The effect of retarded growth upon the length of life span and upon the ultimate body size: one figure. J Nutr. 1935;10(1):63-79.

17. Byberg L, Melhus H, Gedeborg R, Sundström J, Ahlbom A, Zethelius $B$, et al. Total mortality after changes in leisure time physical activity in 50 year old men: 35 year follow-up of population based cohort. BMJ. 2009:338:24.

18. Sun Q, Townsend MK, Okereke OI, Franco OH, Hu FB, Grodstein F. Physical activity at midlife in relation to successful survival in women at age 70 years or older. Arch Intern Med. 2010;170(2):194-201.

19. Vogel T, Brechat PH, Leprêtre PM, Kaltenbach G, Berthel M, Lonsdorfer J. Health benefits of physical activity in older patients: a review. Int J Clin Pract. 2009;63(2):303-20.

20. Plassman BL, Williams JW Jr, Burke JR, Holsinger T, Benjamin S. Systematic review: factors associated with risk for and possible prevention of cognitive decline in later life. Ann Intern Med. 2010;153(3):182-93.

21. Sofi F, Valecchi D, Bacci D, Abbate R, Gensini GF, Casini A, et al. Physical activity and risk of cognitive decline: a meta-analysis of prospective studies. J Intern Med. 2011;269(1):107-17.

22. Black JE, Zelazny AM, Greenough WT. Capillary and mitochondrial support of neural plasticity in adult rat visual cortex. Exp Neurol. 1991;111(2):204-9.

23. Isaacs KR, Anderson BJ, Alcantara AA, Black JE, Greenough WT. Exercise and the brain: angiogenesis in the adult rat cerebellum after vigorous physical activity and motor skill learning. J Cereb Blood Flow Metab. 1992;12(1):110-9.

24. Sokoloff L, Reivich M, Kennedy C, Rosiers MHD, Patlak CS, Pettigrew $\mathrm{KD}$, et al. The $[14 \mathrm{C}]$ deoxyglucose method for the measurement of local cerebral glucose utilization: theory, procedure, and normal values in the conscious and anesthetized albino rat 1.J Neurochem. 1977;28(5):897-916.

25. Fox PT, Raichle ME. Focal physiological uncoupling of cerebral blood flow and oxidative metabolism during somatosensory stimulation in human subjects. Proc Natl Acad Sci. 1986;83(4):1140-4. 
26. Kraus RM, Stallings HW, Yeager RC, Gavin TP. Circulating plasma VEGF response to exercise in sedentary and endurance-trained men. J Appl Physiol. 2004;96(4):1445-50.

27. Vital T, Stein A, Coelho F, Arantes FJ, Teodorov E, Ferreira Galduróz R. Physical exercise and vascular endothelial growth factor (VEGF) in elderly: a systematic review. Arch Gerontol Geriatr. 2014;59:548.

28. Kim H, Lee S-H, Kim S-S, Yoo J-H, Kim C-J. The influence of maternal treadmill running during pregnancy on short-term memory and hippocampal cell survival in rat pups. Int J Dev Neurosci. 2007;25(4):243-9.

29. Lou S, Liu J, Chang H, Chen P. Hippocampal neurogenesis and gene expression depend on exercise intensity in juvenile rats. Brain Res. 2008;1210:48-55.

30. Van Praag H, Kempermann G, Gage FH. Running increases cell proliferation and neurogenesis in the adult mouse dentate gyrus. Nat Neurosci. 1999;2(3):266-70.

31. Van Praag H, Shubert T, Zhao C, Gage FH. Exercise enhances learning and hippocampal neurogenesis in aged mice. J Neurosci. 2005;25(38):8680-5.

32. Van Praag H, Christie BR, Sejnowski TJ, Gage FH. Running enhances neurogenesis, learning, and long-term potentiation in mice. Proc Natl Acad Sci. 1999;96(23):13427-31.

33. Hillman $\mathrm{CH}$, Erickson $\mathrm{Kl}$, Kramer AF. Be smart, exercise your heart: exercise effects on brain and cognition. Nat Rev Neurosci. 2008;9(1):58-65.

34. Kronenberg G, Bick-Sander A, Bunk E, Wolf C, Ehninger D, Kempermann G. Physical exercise prevents age-related decline in precursor cell activity in the mouse dentate gyrus. Neurobiol Aging. 2006;27(10):1505-13.

35. Creer DJ, Romberg C, Saksida LM, van Praag H, Bussey TJ. Running enhances spatial pattern separation in mice. Proc Natl Acad Sci. 2010;107(5):2367-72.

36. Lazarov O, Marr RA. Neurogenesis and Alzheimer's disease: at the crossroads. Exp Neurol. 2010;223(2):267-81.

37. Adlard PA, Perreau VM, Pop V, Cotman CW. Voluntary exercise decreases amyloid load in a transgenic model of Alzheimer's disease. J Neurosci. 2005;25(17):4217-21.

38. Um H-S, Kang E-B, Koo J-H, Kim H-T, Kim E-J, Yang C-H, et al. Treadmill exercise represses neuronal cell death in an aged transgenic mouse model of Alzheimer's disease. Neurosci Res. 2011;69(2):161-73.

39. Erickson KI, Voss MW, Prakash RS, Basak C, Szabo A, Chaddock L, et al. Exercise training increases size of hippocampus and improves memory. Proc Natl Acad Sci. 2011;108(7):3017-22.

40. MacRae PG, Spirduso WW, Walters TJ, Farrar RP, Wilcox RE. Endurance training effects on striatal D2 dopamine receptor binding and striatal dopamine metabolites in presenescent older rats. Psychopharmacology. 1987:92(2):236-40.

41. Poulton NP, Muir GD. Treadmill training ameliorates dopamine loss but not behavioral deficits in hemi-parkinsonian rats. Exp Neurol. 2005;193(1):181-97.

42. Ngandu T, von Strauss E, Helkala EL, Winblad B, Nissinen A, Tuomilehto J, et al. Education and dementia: what lies behind the association? Neurology. 2007;69(14):1442-50.

43. Stern Y, Gurland B, Tatemichi TK, Tang MX, Wilder D, Mayeux R. Influence of education and occupation on the incidence of Alzheimer's disease. JAMA. 1994:271(13):1004-10.

44. Wang H-X, Gustafson DR, Kivipelto M, Pedersen NL, Skoog I, Windblad $B$, et al. Education halves the risk of dementia due to apolipoprotein $\varepsilon 4$ allele: a collaborative study from the Swedish Brain Power initiative. Neurobiol Aging. 2012;33(5):1007-e1.

45. Ferrari C, Nacmias B, Bagnoli S, Piaceri I, Lombardi G, Pradella S, et al. Imaging and cognitive reserve studies predict dementia in presymptomatic Alzheimer's disease subjects. Neurodegener Dis. 2014;13(2-3):157-9.

46. Brayne C, Ince PG, Keage HAD, McKeith IG, Matthews FE, Polvikoski T, et al. Education, the brain and dementia: neuroprotection or compensation? EClipSE Collaborative Members Brain. 2010;133(8):2210-6.

47. Valenzuela MJ, Sachdev P. Brain reserve and dementia: a systematic review. Psychol Med. 2006:36(4):441.

48. Nithianantharajah J, Hannan AJ. Enriched environments, experiencedependent plasticity and disorders of the nervous system. Nat Rev Neurosci. 2006;7(9):697-709.

49. Harraan D. Aging: a theory based on free radical and radiation chemistry. 1955.
50. Bokov A, Chaudhuri A, Richardson A. The role of oxidative damage and stress in aging. Mech Ageing Dev. 2004;125(10-11):811-26.

51. Farkhondeh T, Samarghandian S, Shahri AMP, Samini F. The neuroprotective effects of thymoquinone: a review. Dose Response. 2018:16(2):1559325818761455.

52. Samarghandian S, Borji A, Farkhondeh T. Evaluation of antidiabetic activity of carnosol (phenolic diterpene in rosemary) in streptozotocininduced diabetic rats. Cardiovasc Hematol Disord Drug Targets. 2017:17(1):11-7.

53. Samarghandian S, Azimi-Nezhad M, Borji A, Farkhondeh T. Effect of crocin on aged rat kidney through inhibition of oxidative stress and proinflammatory state. Phytother Res. 2016;30(8):1345-53. https://doi. org/10.1002/ptr.5638

54. Kensler TW, Wakabayashi N, Biswal S. Cell survival responses to environmental stresses via the Keap1-Nrf2-ARE pathway. Annu Rev Pharmacol Toxicol. 2007:47:89-116.

55. Gorrini C, Harris IS, MakTW. Modulation of oxidative stress as an anticancer strategy. Nat Rev Drug Discovery. 2013;12(12):931-47.

56. Peng C, Wang X, Chen J, Jiao R, Wang L, Li YM, et al. Biology of ageing and role of dietary antioxidants. BioMed Research International. 2014;2014:278.

57. Harman D. The biologic clock: the mitochondria? J Am Geriatr Soc. 1972;20(4):145-7.

58. Scialò F, Sriram A, Fernández-Ayala D, Gubina N, Lõhmus M, Nelson $\mathrm{G}$, et al. Mitochondrial ROS produced via reverse electron transport extend animal lifespan. Cell Metab. 2016;23(4):725-34.

59. Raamsdonk JM, Hekimi S. Deletion of the mitochondrial superoxide dismutase sod-2 extends lifespan in Caenorhabditis elegans. PLoS genet. 2009:5(2):e1000361.

60. Mockett RJ, Bayne ACV, Kwong LK, Orr WC, Sohal RS. Ectopic expression of catalase in Drosophila mitochondria increases stress resistance but not longevity. Free Radical Biol Med. 2003;34(2):207-17.

61. Pérez VI, Van Remmen H, Bokov A, Epstein CJ, Vijg J, Richardson A. The overexpression of major antioxidant enzymes does not extend the lifespan of mice. Aging Cell. 2009;8(1):73-5.

62. Zhang Y, Ikeno Y, Qi W, Chaudhuri A, Li Y, Bokov A, et al. Mice deficient in both Mn superoxide dismutase and glutathione peroxidase-1 have increased oxidative damage and a greater incidence of pathology but no reduction in longevity. Journals of Gerontology Series A: Biomedical Sciences and Medical Sciences. 2009;64(12):1212-20.

63. Schaar CE, Dues DJ, Spielbauer KK, Machiela E, Cooper JF, Senchuk M, et al. Mitochondrial and cytoplasmic ROS have opposing effects on lifespan. PLoS genet. 2015;11(2):e1004972.

64. Veal EA, Day AM, Morgan BA. Hydrogen peroxide sensing and signaling. Mol Cell. 2007;26(1):1-14

65. Halliwell B. Role of free radicals in the neurodegenerative diseases. Drugs Aging. 2001;18(9):685-716.

66. Förstermann U, Sessa WC. Nitric oxide synthases: regulation and function. Eur Heart J. 2012;33(7):829-37.

67. Herring A, Blome M, Ambrée O, Sachser N, Paulus W, Keyvani K. Reduction of cerebral oxidative stress following environmental enrichment in mice with Alzheimer-like pathology. Brain Pathol. 2010;20(1):166-75.

68. Park L, Anrather J, Girouard H, Zhou P, ladecola C. Nox2-derived reactive oxygen species mediate neurovascular dysregulation in the aging mouse brain. J Cereb Blood Flow Metab. 2007;27(12):1908-18.

69. Cini M, Moretti A. Studies on lipid peroxidation and protein oxidation in the aging brain. Neurobiol Aging. 1995;16(1):53-7.

70. Dei R, Takeda A, Niwa H, Li M, Nakagomi Y, Watanabe M, et al. Lipid peroxidation and advanced glycation end products in the brain in normal aging and in Alzheimer's disease. Acta Neuropathol. 2002;104(2):113-22.

71. Mooradian AD, Lung CC, Shah G, Mahmoud S, Pinnas JL. Age-related changes in tissue content of malondialdehyde-modified proteins. Life Sci. 1994:55(20):1561-6.

72. Giusto NM, Salvador GA, Castagnet PI, Pasquare SJ, De Boschero MGI. Age-associated changes in central nervous system glycerolipid composition and metabolism. Neurochem Res. 2002;27(11):1513-23.

73. Ulmann L, Mimouni V, Roux S, Porsolt R, Poisson JP. Brain and hippocampus fatty acid composition in phospholipid classes of agedrelative cognitive deficit rats. PLEFA. 2001;64(3):189-95. 
74. Lynch MA. Analysis of the mechanisms underlying the age-related impairment in long-term potentiation in the rat. Rev Neurosci. 1998;9(3):169-202.

75. Papaioannou N, Tooten PCJ, van Ederen AM, Bohl JRE, Rofina J, Tsangaris $T$, et al. Immunohistochemical investigation of the brain of aged dogs. I. Detection of neurofibrillary tangles and of 4-hydroxynonenal protein, an oxidative damage product, in senile plaques. Amyloid. 2001;8(1):11-21.

76. Malenka RC, Bear MF. LTP and LTD: an embarrassment of riches. Neuron. 2004;44(1):5-21.

77. Artola A, Von Frijtag JC, Fermont PCJ, Gispen WH, Schrama LH, Kamal A, et al. Long-lasting modulation of the induction of LTD and LTP in rat hippocampal CA1 by behavioural stress and environmental enrichment. Eur J Neurosci. 2006;23(1):261-72.

78. Rampon C, Tang Y-P, Goodhouse J, Shimizu E, Kyin M, Tsien JZ. Enrichment induces structural changes and recovery from nonspatial memory deficits in CA1 NMDAR1-knockout mice. Nat Neurosci. 2000;3(3):238-44

79. Tang YP, Wang H, Feng R, Kyin M, Tsien JZ. Differential effects of enrichment on learning and memory function in NR2B transgenic mice. Neuropharmacology. 2001;41(6):779-90.

80. Head E, Liu J, Hagen TM, Muggenburg BA, Milgram NW, Ames BN, et al. Oxidative damage increases with age in a canine model of human brain aging. J Neurochem. 2002;82(2):375-81.

81. Smith CD, Carney JM, Starke-Reed PE, Oliver CN, Stadtman ER, Floyd RA, et al. Excess brain protein oxidation and enzyme dysfunction in normal aging and in Alzheimer disease. Proc Natl Acad Sci. 1991;88(23):10540-3.

82. Çakatay U, Telci A, Kayali R, Tekeli F, Akcay T, Sivas A. Relation of oxidative protein damage and nitrotyrosine levels in the aging rat brain. Exp Gerontol. 2001;36(2):221-9.

83. Aksenova MV, Aksenov MY, Carney JM, Butterfield DA. Protein oxidation and enzyme activity decline in old brown Norway rats are reduced by dietary restriction. Mech Ageing Dev. 1998;100(2):157-68.

84. Dubey A, Forster MJ, Sohal RS. Effect of the spin-trapping compound $\mathrm{N}$-tert-butyl-a-phenylnitrone on protein oxidation and life span. Arch Biochem Biophys. 1995;324(2):249-54

85. Nicolle MM, Gonzalez J, Sugaya K, Baskerville KA, Bryan D, Lund K, et al. Signatures of hippocampal oxidative stress in aged spatial learningimpaired rodents. Neuroscience. 2001;107(3):415-31.

86. Melov S, Schneider JA, Day BJ, Hinerfeld D, Coskun P, Mirra SS, et al. A novel neurological phenotype in mice lacking mitochondrial manganese superoxide dismutase. Nat Genet. 1998;18(2):159-63.

87. Paul A, Belton A, Nag S, Martin I, Grotewiel MS, Duttaroy A. Reduced mitochondrial SOD displays mortality characteristics reminiscent of natural aging. Mech Ageing Dev. 2007;128(11-12):706-16.

88. Calabrese V, Scapagnini G, Ravagna A, Bella R, Butterfield DA, Calvani M, et al. Disruption of thiol homeostasis and nitrosative stress in the cerebrospinal fluid of patients with active multiple sclerosis: evidence for a protective role of acetylcarnitine. Neurochem Res. 2003;28(9):1321-8.

89. Calabrese V, Scapagnini G, Colombrita C, Ravagna A, Pennisi G, Stella $A M G$, et al. Redox regulation of heat shock protein expression in aging and neurodegenerative disorders associated with oxidative stress: a nutritional approach. Amino Acids. 2003;25(3-4):437-44.

90. Calabrese V, Scapagnini G, Ravagna A, Fariello RG, Giuffrida Stella AM, Abraham NG. Regional distribution of heme oxygenase, HSP70, and glutathione in brain: relevance for endogenous oxidant/antioxidant balance and stress tolerance. J Neurosci Res. 2002;68(1):65-75.

91. Motterlini R, Foresti R, Bassi R, Green CJ. Curcumin, an antioxidant and anti-inflammatory agent, induces heme oxygenase- 1 and protects endothelial cells against oxidative stress. Free Radical Biol Med. 2000;28(8):1303-12

92. Mayer RJ. From neurodegeneration to neurohomeostasis: the role of ubiquitin. Drug News Perspect. 2003;16(2):103-8.

93. Calabrese V, Scapagnini G, Ravagna A, Stella AMG, Butterfield DA. Molecular chaperones and their roles in neural cell differentiation. Dev Neurosci. 2002;24(1):1-13.

94. Butterfield DA, Pocernich CB, Drake J. Elevated glutathione as a therapeutic strategy in Alzheimer's disease. Drug Dev Res. 2002;56(3):428-37.

95. Drake J, Sultana R, Aksenova M, Calabrese V, Butterfield DA. Elevation of mitochondrial glutathione by $\gamma$-glutamylcysteine ethyl ester protects mitochondria against peroxynitrite-induced oxidative stress. J Neurosci Res. 2003;74(6):917-27.

96. Poon HF, Calabrese V, Scapagnini G, Butterfield DA. Free radicals: key to brain aging and heme oxygenase as a cellular response to oxidative stress. J Gerontol A Biol Sci Med Sci. 2004:59(5):M478-93.

97. Turner CP, Panter SS, Sharp FR. Anti-oxidants prevent focal rat brain injury as assessed by induction of heat shock proteins (HSP70, HO-1/ HSP32, HSP47) following subarachnoid injections of lysed blood. Mol Brain Res. 1999:65(1):87-102.

98. Dringen R, Hirrlinger J. Glutathione pathways in the brain. 2003.

99. Calabrese V, Bates TE, Stella AMG. NO synthase and NO-dependent signal pathways in brain aging and neurodegenerative disorders: the role of oxidant/antioxidant balance. Neurochem Res. 2000;25(9):1315-41.

100. Calabrese V, Copani A, Testa D, Ravagna A, Spadaro F, Tendi E, et al. Nitric oxide synthase induction in astroglial cell cultures: effect on heat shock protein 70 synthesis and oxidant/antioxidant balance. J Neurosci Res. 2000;60(5):613-22.

101. Siekevitz P. Powerhouse of the cell. Sci Am. 1957;197(1):131-44

102. McBride HM, Neuspiel M, Wasiak S. Mitochondria: more than just a powerhouse. Curr Biol. 2006;16(14):R551-60.

103. Kim I, Rodriguez-Enriquez S, Lemasters JJ. Selective degradation of mitochondria by mitophagy. Arch Biochem Biophys. 2007;462(2):245-53.

104. Hou Y, Ouyang X, Wan R, Cheng H, Mattson MP, Cheng A. Mitochondrial superoxide production negatively regulates neural progenitor proliferation and cerebral cortical development. Stem cells. 2012;30(11):2535-47.

105. Yun J, Finkel T. Mitohormesis. Cell Metab. 2014;19(5):757-66.

106. Raefsky SM, Mattson MP. Adaptive responses of neuronal mitochondria to bioenergetic challenges: roles in neuroplasticity and disease resistance. Free Radical Biol Med. 2017:102:203-16.

107. Nunnari J, Suomalainen A. Mitochondria: in sickness and in health. Cell. 2012;148(6):1145-59.

108. Held NM, Houtkooper RH. Mitochondrial quality control pathways as determinants of metabolic health. BioEssays. 2015:37(8):867-76.

109. Gonzalez-Freire M, De Cabo R, Bernier M, Sollott SJ, Fabbri E, Navas P, et al. Reconsidering the role of mitochondria in aging. J Gerontol Series A. 2015;70(11):1334-42.

110. Ryan MT, Hoogenraad NJ. Mitochondrial-nuclear communications. Annu Rev Biochem. 2007;76:701-22.

111. Mishra P, Chan DC. Mitochondrial dynamics and inheritance during cell division, development and disease. Nat Rev Mol Cell Biol. 2014;15(10):634-46.

112. Friedman JR, Nunnari J. Mitochondrial form and function. Nature. 2014;505(7483):335-43.

113. Fang EF, Scheibye-Knudsen M, Chua KF, Mattson MP, Croteau DL, Bohr VA. Nuclear DNA damage signalling to mitochondria in ageing. Nat Rev Mol Cell Biol. 2016;17(5):308-21.

114. Gomes AP, Price NL, Ling AJY, Moslehi JJ, Montgomery MK, Rajman $L$, et al. Declining NAD+ induces a pseudohypoxic state disrupting nuclear-mitochondrial communication during aging. Cell. 2013;155(7):1624-38.

115. Lee S-J, Hwang AB, Kenyon C. Inhibition of respiration extends $C$. elegans life span via reactive oxygen species that increase HIF-1 activity. Curr Biol. 2010;20(23):2131-6.

116. Irfannuddin I, Santoso B, Zein RH, Naufal AF. The effect of aerobic exercise and caloric restriction on mice's brain tissue PGC-1 a levels and their memory abilities. New York: IOP Publishing; 2019.

117. Yankner BA, Lu T, Loerch P. The aging brain. Annu Rev Pathol Mech Dis. 2008:3:41-66

118. Mattson MP, Gleichmann M, Cheng A. Mitochondria in neuroplasticity and neurological disorders. Neuron. 2008;60(5):748-66.

119. Wallace DC. A mitochondrial paradigm of metabolic and degenerative diseases, aging, and cancer: a dawn for evolutionary medicine. Annu Rev Genet. 2005;39:359-407.

120. Mattson MP. Apoptosis in neurodegenerative disorders. Nat Rev Mol Cell Biol. 2000;1 (2):120-30. 
121. Stahon KE, Bastian C, Griffith S, Kidd GJ, Brunet S, Baltan S. Age-related changes in axonal and mitochondrial ultrastructure and function in white matter. J Neurosci. 2016;36(39):9990-10001.

122. Morozov YM, Datta D, Paspalas CD, Arnsten AFT. Ultrastructural evidence for impaired mitochondrial fission in the aged rhesus monkey dorsolateral prefrontal cortex. Neurobiol Aging. 2017;51:9-18.

123. Kim GW, Chan PH. Oxidative stress and neuronal DNA fragmentation mediate age-dependent vulnerability to the mitochondrial toxin, 3-nitropropionic acid, in the mouse striatum. Neurobiol Dis. 2001;8(1):114-26

124. Santos RX, Correia SC, Zhu X, Smith MA, Moreira PI, Castellani RJ, et al. Mitochondrial DNA oxidative damage and repair in aging and Alzheimer's disease. Antioxid Redox Signal. 2013;18(18):2444-57.

125. Lores-Arnaiz S, Lombardi P, Karadayian AG, Orgambide F, Cicerchia D, Bustamante J. Brain cortex mitochondrial bioenergetics in synaptosomes and non-synaptic mitochondria during aging. Neurochem Res. 2016;41(1-2):353-63.

126. Yao J, Hamilton RT, Cadenas E, Brinton RD. Decline in mitochondrial bioenergetics and shift to ketogenic profile in brain during reproductive senescence. BBA Gener Subj. 2010;1800(10):1121-6.

127. Pandya JD, Grondin R, Yonutas HM, Haghnazar H, Gash DM, Zhang Z, et al. Decreased mitochondrial bioenergetics and calcium buffering capacity in the basal ganglia correlates with motor deficits in a nonhuman primate model of aging. Neurobiol Aging. 2015;36(5):1903-13.

128. Pollard AK, Craig EL, Chakrabarti L. Mitochondrial complex 1 activity measured by spectrophotometry is reduced across all brain regions in ageing and more specifically in neurodegeneration. PLOS ONE. 2016;11(6):e0157405.

129. Leslie SW, Chandler LJ, Barr EM, Farrar RP. Reduced calcium uptake by rat brain mitochondria and synaptosomes in response to aging. Brain Res. 1985;329(1-2):177-83.

130. Brown MR, Geddes JW, Sullivan PG. Brain region-specific, age-related, alterations in mitochondrial responses to elevated calcium. J Bioenerg Biomembr. 2004;36(4):401-6.

131. Braidy N, Poljak A, Grant R, Jayasena T, Mansour H, Chan-Ling T, et al. Mapping NAD+ metabolism in the brain of ageing Wistar rats: potential targets for influencing brain senescence. Biogerontology. 2014;15(2):177-98.

132. Fang EF, Lautrup S, Hou Y, Demarest TG, Croteau DL, Mattson MP, et al. NAD+ in aging: molecular mechanisms and translational implications. Trends Mol Med. 2017;23(10):899-916.

133. Lin D-T, Wu J, Holstein D, Upadhyay G, Rourk W, Muller E, et al. Ca2+ signaling, mitochondria and sensitivity to oxidative stress in aging astrocytes. Neurobiol Aging. 2007;28(1):99-111.

134. Ghosh D, LeVault KR, Barnett AJ, Brewer GJ. A reversible early oxidized redox state that precedes macromolecular ROS damage in aging nontransgenic and 3xTg-AD mouse neurons. J Neurosci. 2012;32(17):5821-32.

135. Olovnikov AM. Telomeres, telomerase, and aging: origin of the theory. Exp Gerontol. 1996;31(4):443-8.

136. Muraki K, Nyhan K, Han L, Murnane JP. Mechanisms of telomere loss and their consequences for chromosome instability. Front Oncol. 2012;2:135.

137. Blackburn EH, Epel ES, Lin J. Human telomere biology: a contributory and interactive factor in aging, disease risks, and protection. Science. 2015;350(6265):1193-8.

138. Harley $C B$, Futcher $A B$, Greider CW. Telomeres shorten during ageing of human fibroblasts. Nature. 1990;345(6274):458-60.

139. Hayflick L, Moorhead PS. The serial cultivation of human diploid cell strains. Exp Cell Res. 1961;25(3):585-621.

140. Nandakumar J, Cech TR. Finding the end: recruitment of telomerase to telomeres. Nat Rev Mol Cell Biol. 2013:14(2):69-82.

141. Marión RM, Blasco MA. Telomeres and telomerase in adult stem cells and pluripotent embryonic stem cells. The Cell Biology of Stem Cells: Springer; 2010. p. 118-31.

142. Yang C, Przyborski S, Cooke MJ, Zhang X, Stewart R, Anyfantis G, et al. A key role for telomerase reverse transcriptase unit in modulating human embryonic stem cell proliferation, cell cycle dynamics, and in vitro differentiation. Stem Cells. 2008;26(4):850-63.
143. Takubo K, Aida J, Izumiyama-Shimomura N, Ishikawa N, Sawabe M, Kurabayashi R, et al. Changes of telomere length with aging. Geriatr Gerontol Int. 2010;10:S197-206.

144. Mosch B, Morawski M, Mittag A, Lenz D, Tarnok A, Arendt T. Aneuploidy and DNA replication in the normal human brain and Alzheimer's disease. J Neurosci. 2007;27(26):6859-67.

145. Fischer HG, Morawski M, Brückner MK, Mittag A, Tarnok A, Arendt T Changes in neuronal DNA content variation in the human brain during aging. Aging Cell. 2012;11(4):628-33.

146. Bär C, Blasco MA. Telomeres and telomerase as therapeutic targets to prevent and treat age-related diseases. F1000Research. 2016;5:78

147. Wright WE, Piatyszek MA, Rainey WE, Byrd W, Shay JW. Telomerase activity in human germline and embryonic tissues and cells. Dev Genet. 1996;18(2):173-9.

148. Klapper W, Shin T, Mattson MP. Differential regulation of telomerase activity and TERT expression during brain development in mice. J Neurosci Res. 2001;64(3):252-60.

149. Eitan E, Tichon A, Priel E. Dissociation between telomerase activity and expression during mice cortical development due to a DNA-bound telomerase inhibitor. Matters Select. 2016;2(5):e201604000008.

150. Coviello-McLaughlin GM, Prowse KR. Telomere length regulation during postnatal development and ageing in Mus spretus. Nucleic Acids Res. 1997;25(15):3051-8

151. Cheng A, Shinya K, Wan R, Tang S, Miura T, Tang H, et al. Telomere protection mechanisms change during neurogenesis and neuronal maturation: newly generated neurons are hypersensitive to telomere and DNA damage. J Neurosci. 2007:27(14):3722-33.

152. Rolyan H, Scheffold A, Heinrich A, Begus-Nahrmann Y, Langkopf BH, Hölter SM, et al. Telomere shortening reduces Alzheimer's disease amyloid pathology in mice. Brain. 2011;134(7):2044-56.

153. Jaskelioff M, Muller FL, Paik J-H, Thomas E, Jiang S, Adams AC, et al. Telomerase reactivation reverses tissue degeneration in aged telomerasedeficient mice. Nature. 2011:469(7328):102-6.

154. Jurk D, Wang C, Miwa S, Maddick M, Korolchuk V, Tsolou A, et al. Postmitotic neurons develop a p21-dependent senescence-like phenotype driven by a DNA damage response. Aging Cell. 2012;1 1(6):996-1004.

155. Childs BG, Baker DJ, Kirkland JL, Campisi J, Van Deursen JM. Senescence and apoptosis: dueling or complementary cell fates? EMBO Rep. 2014;15(11):1139-53.

156. Molofsky AV, Slutsky SG, Joseph NM, He S, Pardal R, Krishnamurthy J, et al. Increasing p16 INK4a expression decreases forebrain progenitors and neurogenesis during ageing. Nature. 2006;443(7110):448-52.

157. Wright LS, Prowse KR, Wallace K, Linskens MHK, Svendsen CN. Human progenitor cells isolated from the developing cortex undergo decreased neurogenesis and eventual senescence following expansion in vitro. Exp Cell Res. 2006;312(11):2107-20.

158. Ain Q, Schmeer C, Penndorf D, Fischer M, Bondeva T, Förster M, et al. Cell cycle-dependent and-independent telomere shortening accompanies murine brain aging. Aging (Albany NY). 2018;10(11):3397.

159. Gampawar P, Schmidt R, Schmidt H. Leukocyte Telomere Length is related to brain parenchymal fraction and attention/speed in the elderly: Results of the Austrian Stroke Prevention Study. Front Psych. 2020:11:100.

160. Puhlmann LMC, Valk SL, Engert V, Bernhardt BC, Lin J, Epel ES, et al. Association of short-term change in leukocyte telomere length with cortical thickness and outcomes of mental training among healthy adults: a randomized clinical trial. JAMA Netw Open. 2019;2(9):e199687

161. Azor AM, Cole JH, Holland AJ, Dumba M, Patel MC, Sadlon A, et al. Increased brain age in adults with Prader-Willi syndrome. Neurolmage Clin. 2019:21:101664.

162. Delves PJ, Roitt IM. The immune system. N Engl J Med. 2000;343(1):37-49.

163. Gruver AL, Hudson LL, Sempowski GD. Immunosenescence of ageing. The Journal of Pathology: A Journal of the Pathological Society of Great Britain and Ireland. 2007;211(2):144-56.

164. Pawelec G, Solana R. Immunosenescence. Immunol Today. 1997;18(11):514-5. 
165. Franceschi $C$, Bonafè $M$, Valensin S, Olivieri F, De Luca M, Ottaviani E, et al. Inflamm-aging: an evolutionary perspective on immunosenescence. Ann NY Acad Sci. 2000;908(1):244-54.

166. Salminen A, Kauppinen A, Kaarniranta K. Emerging role of NF-KB signaling in the induction of senescence-associated secretory phenotype (SASP). Cell Signal. 2012;24(4):835-45.

167. Özcan S, Alessio N, Acar MB, Mert E, Omerli F, Peluso G, et al. Unbiased analysis of senescence associated secretory phenotype (SASP) to identify common components following different genotoxic stresses. Aging (Albany NY). 2016;8(7):1316.

168. Li Q, Verma IM. NF-kB regulation in the immune system. Nat Rev Immunol. 2002;2(10):725-34.

169. Hayden MS, Ghosh S. Signaling to NF-KB. Genes Dev. 2004;18(18):2195-224.

170. Baldwin AS Jr. The NF-KB and IKB proteins: new discoveries and insights. Annu Rev Immunol. 1996;14(1):649-81.

171. DiDonato JA, Hayakawa M, Rothwarf DM, Zandi E, Karin M. A cytokineresponsive IKB kinase that activates the transcription factor NF-KB. Nature. 1997;388(6642):548-54.

172. Patten DA, Germain M, Kelly MA, Slack RS. Reactive oxygen species: stuck in the middle of neurodegeneration. J Alzheimers Dis. 2010;20(s2):S357-67.

173. Sallam N, Laher I. Exercise modulates oxidative stress and inflammation in aging and cardiovascular diseases. Oxidat Med Cell Long. 2016;2016:224.

174. Streit WJ, Xue Q-S. The brain's aging immune system. Aging Dis. 2010;1(3):254

175. Yaffe K, Lindquist K, Penninx BW, Simonsick EM, Pahor M, Kritchevsky S, et al. Inflammatory markers and cognition in well-functioning AfricanAmerican and white elders. Neurology. 2003;61(1):76-80.

176. Cronin O, Keohane DM, Molloy MG, Shanahan F. The effect of exercise interventions on inflammatory biomarkers in healthy, physically inactive subjects: a systematic review. QJM. 2017;110(10):629-37.

177. Manuela Crispim Nascimento C, Rodrigues Pereira J, Piresde Andrade L, Garuffi M, Leme Talib L, Vicente Forlenza O, et al. Physical exercise in $\mathrm{MCl}$ elderly promotes reduction of pro-inflammatory cytokines and improvements on cognition and BDNF peripheral levels. Curr Alzheimer Res. 2014;11(8):799-805.

178. Pedersen BK, Bruunsgaard H. Possible beneficial role of exercise in modulating low-grade inflammation in the elderly. Scand J Med Sci Sports. 2003;13(1):56-62.

179. Mosher Kl, Wyss-Coray T. Microglial dysfunction in brain aging and Alzheimer's disease. Biochem Pharmacol. 2014;88(4):594-604.

180. Von Bernhardi R, Eugenín-von Bernhardi L, Eugenín J. Microglial cell dysregulation in brain aging and neurodegeneration. Front Aging Neurosci. 2015:7:124

181. Cagnin A, Brooks DJ, Kennedy AM, Gunn RN, Myers R, Turkheimer FE, et al. In-vivo measurement of activated microglia in dementia. Lancet. 2001:358(9280):461-7.

182. Kim SU, de Vellis J. Microglia in health and disease. J Neurosci Res. 2005;81(3):302-13.

183. Block ML, Zecca L, Hong J-S. Microglia-mediated neurotoxicity: uncovering the molecular mechanisms. Nat Rev Neurosci. 2007:8(1):57-69.

184. Hanisch U-K, Kettenmann H. Microglia: active sensor and versatile effector cells in the normal and pathologic brain. Nat Neurosci. 2007;10(11):1387-94.

185. Liu X, Wu Z, Hayashi Y, Nakanishi H. Age-dependent neuroinflammatory responses and deficits in long-term potentiation in the hippocampus during systemic inflammation. Neuroscience. 2012;216:133-42.

186. Raj DDA, Jaarsma D, Holtman IR, Olah M, Ferreira FM, Schaafsma W, et al. Priming of microglia in a DNA-repair deficient model of accelerated aging. Neurobiol Aging. 2014;35(9):2147-60.

187. Okun E, Griffioen KJ, Mattson MP. Toll-like receptor signaling in neural plasticity and disease. Trends Neurosci. 2011;34(5):269-81.

188. Colonna M, Butovsky O. Microglia function in the central nervous system during health and neurodegeneration. Annu Rev Immunol. 2017;35:441-68.

189. Snow WM, Stoesz BM, Kelly DM, Albensi BC. Roles for NF-kB and gene targets of NF-KB in synaptic plasticity, memory, and navigation. Mol Neurobiol. 2014;49(2):757-70.
190. Bruce AJ, Boling W, Kindy MS, Peschon J, Kraemer PJ, Carpenter MK, et al. Altered neuronal and microglial responses to excitotoxic and ischemic brain injury in mice lacking TNF receptors. Nat Med. 1996;2(7):788-94

191. Sullivan PG, Bruce-Keller AJ, Rabchevsky AG, Christakos S, Clair DKS, Mattson MP, et al. Exacerbation of damage and altered NF-KB activation in mice lacking tumor necrosis factor receptors after traumatic brain injury. J Neurosci. 1999;19(15):6248-56.

192. Montgomery SL, Mastrangelo MA, Habib D, Narrow WC, Knowlden SA, Wright TW, et al. Ablation of TNF-RI/RII expression in Alzheimer's disease mice leads to an unexpected enhancement of pathology: implications for chronic pan-TNF-a suppressive therapeutic strategies in the brain. Am J Pathol. 2011;179(4):2053-70.

193. Mattson MP, Rychlik B. Glia protect hippocampal neurons against excitatory amino acid-induced degeneration: involvement of fibroblast growth factor. Int J Dev Neurosci. 1990;8(4):399-415.

194. Camandola S, Mattson MP. Brain metabolism in health, aging, and neurodegeneration. EMBO J. 2017;36(11):1474-92.

195. Rose CR, Felix L, Zeug A, Dietrich D, Reiner A, Henneberger C. Astroglial glutamate signaling and uptake in the hippocampus. Front Mol Neurosci. 2018;10:451

196. Barger SW, Hörster D, Furukawa K, Goodman Y, Krieglstein J, Mattson MP. Tumor necrosis factors alpha and beta protect neurons against amyloid beta-peptide toxicity: evidence for involvement of a kappa B-binding factor and attenuation of peroxide and $\mathrm{Ca}^{2+}$ accumulation. Proc Natl Acad Sci. 1995;92(20):9328-32.

197. Pennypacker KR, Kassed CA, Eidizadeh S, Saporta S, Sanberg PR, Willing AE. NF-kB p50 is increased in neurons surviving hippocampal injury. Exp Neurol. 2001;172(2):307-19.

198. Bhakar AL, Tannis L-L, Zeindler C, Russo MP, Jobin C, Park DS, et al. Constitutive nuclear factor-KB activity is required for central neuron survival. J Neurosci. 2002;22(19):8466-75.

199. Mattson MP. NF-KB in the survival and plasticity of neurons. Neurochem Res. 2005;30(6):883-93.

200. Chen L, Liu L, Yin J, Luo Y, Huang S. Hydrogen peroxide-induced neuronal apoptosis is associated with inhibition of protein phosphatase $2 \mathrm{~A}$ and 5, leading to activation of MAPK pathway. Int J Biochem Cell Biol. 2009:41(6):1284-95.

201. Chongthammakun V, Sanvarinda Y, Chongthammakun S. Reactive oxygen species production and MAPK activation are implicated in tetrahydrobiopterin-induced SH-SY5Y cell death. Neurosci Lett. 2009:449(3):178-82

202. Song YS, Park HJ, Kim SY, Lee SH, Yoo HS, Lee HS, et al. Protective role of BCl-2 on $\beta$-amyloid-induced cell death of differentiated PC12 cells: reduction of NF-KB and p38 MAP kinase activation. Neurosci Res. 2004;49(1):69-80

203. Sastre M, Klockgether T, Heneka MT. Contribution of inflammatory processes to Alzheimer's disease: molecular mechanisms. Int J Dev Neurosci. 2006;24(2-3):167-76.

204. Cho HJ, Kim SK, Jin SM, Hwang EM, Kim YS, Huh K, et al. IFN- $\gamma$-induced BACE1 expression is mediated by activation of JAK2 and ERK1/2 signaling pathways and direct binding of STAT1 to BACE1 promoter in astrocytes. Glia. 2007;55(3):253-62.

205. Solon-Biet SM, Mitchell SJ, de Cabo R, Raubenheimer D, Le Couteur DG, Simpson SJ. Macronutrients and caloric intake in health and longevity. J Endocrinol. 2015;226(1):R17.

206. Johnson SC. Nutrient sensing, signaling and ageing: the role of IGF-1 and mTOR in ageing and age-related disease. Biochem Cell Biol Ageing. 2018:85:49-97.

207. Wiley CD, Campisi J. From ancient pathways to aging cells_-connecting metabolism and cellular senescence. Cell Metab. 2016;23(6):1013-21.

208. Sun X, Komatsu T, Lim J, Laslo M, Yolitz J, Wang C, et al. Nutrientdependent requirement for SOD1 in lifespan extension by protein restriction in Drosophila melanogaster. Aging Cell. 2012;11(5):783-93.

209. Chandrasekaran A, Idelchik MPS, Melendez JA. Redox control of senescence and age-related disease. Redox Biol. 2017;11:91-102.

210. Kapeller R, Cantley LC. Phosphatidylinositol 3-kinase. BioEssays. 1994;16(8):565-76. 
211. Vanhaesebroeck B, Waterfield MD. Signaling by distinct classes of phosphoinositide 3-kinases. Exp Cell Res. 1999;253(1):239-54.

212. Bartke A, Brown-Borg H, Mattison J, Kinney B, Hauck S, Wright C. Prolonged longevity of hypopituitary dwarf mice. Exp Gerontol. 2001;36(1):21-8.

213. Sonntag WE, Deak F, Ashpole N, Csiszar A, Toth P, Freeman W, et al. Insulin-like growth factor-1 in CNS and cerebrovascular aging. Front Aging Neurosci. 2013;5:27.

214. Sonntag WE, Csiszar A, De Cabo R, Ferrucci L, Ungvari Z. Diverse roles of growth hormone and insulin-like growth factor-1 in mammalian aging: progress and controversies. J Gerontol Series A. 2012;67(6):587-98.

215. Breese $C R$, Ingram RL, Sonntag WE. Influence of age and long-term dietary restriction on plasma insulin-like growth factor-1 (IGF-1), IGF-1 gene expression, and IGF-1 binding proteins. J Gerontol. 1991;46(5):B180-7.

216. D'Costa AP, Ingram RL, Lenham JE, Sonntag WE. The regulation and mechanisms of action of growth hormone and insulin-like growth factor 1 during normal ageing. J Reprod Fertil Suppl. 1993;46:87-98.

217. Khan AS, Sane DC, Wannenburg T, Sonntag WE. Growth hormone, insulin-like growth factor-1 and the aging cardiovascular system. Cardiovasc Res. 2002;54(1):25-35.

218. Sartorio A, Cattaneo M, Bucciarelli P, Bottasso B, Porretti S, Epaminonda $\mathrm{P}$, et al. Alterations of haemostatic and fibrinolytic markers in adult patients with growth hormone deficiency and with acromegaly. Exp Clin Endocrinol Diabetes. 2000;108(07):486-92.

219. Sonntag WE, Carter CS, Ikeno Y, Ekenstedt K, Carlson CS, Loeser RF, et al. Adult-onset growth hormone and insulin-like growth factor I deficiency reduces neoplastic disease, modifies age-related pathology, and increases life span. Endocrinology. 2005;146(7):2920-32.

220. Higashi Y, Sukhanov S, Anwar A, Shai S-Y, Delafontaine P. Aging, atherosclerosis, and IGF-1. J Gerontol Series A. 2012;67(6):626-39.

221. Sutherland GR, Dix GA, Auer RN. Effect of age in rodent models of focal and forebrain ischemia. Stroke. 1996;27(9):1663-7.

222. DiNapoli VA, Huber JD, Houser K, Li X, Rosen CL. Early disruptions of the blood-brain barrier may contribute to exacerbated neuronal damage and prolonged functional recovery following stroke in aged rats. Neurobiol Aging. 2008;29(5):753-64.

223. Tan Z, Li X, Kelly KA, Rosen CL, Huber JD. Plasminogen activator inhibitor type 1 derived peptide, EEIIMD, diminishes cortical infarct but fails to improve neurological function in aged rats following middle cerebral artery occlusion. Brain Res. 2009;1281:84-90.

224. Bake S, Selvamani A, Cherry J, Sohrabji F. Blood brain barrier and neuroinflammation are critical targets of IGF-1-mediated neuroprotection in stroke for middle-aged female rats. PloS ONE. 2014;9(3):e91427.

225. Yan H, Mitschelen M, Toth P, Ashpole NM, Farley JA, Hodges EL, et al. Endothelin-1-induced focal cerebral ischemia in the growth hormone/IGF-1 deficient Lewis Dwarf rat. J Gerontol Series A. 2014;69(11):1353-62.

226. Pirger Z, Naskar S, László Z, Kemenes G, Reglődi D, Kemenes I. Reversal of age-related learning deficiency by the vertebrate PACAP and IGF-1 in a novel invertebrate model of aging: the pond snail (Lymnaea stagnalis). J Gerontol Series A. 2014;69(11):1331-8.

227. Deak F, Sonntag WE. Aging, synaptic dysfunction, and insulin-like growth factor (IGF)-1. J Gerontol Series A. 2012;67(6):611-25.

228. Bailey-Downs LC, Sosnowska D, Toth P, Mitschelen M, Gautam T, Henthorn JC, et al. Growth hormone and IGF-1 deficiency exacerbate high-fat diet-induced endothelial impairment in obese lewis dwarf rats: implications for vascular aging. J Gerontol Series A. 2012;67(6):553-64.

229. Milman S, Atzmon G, Huffman DM, Wan J, Crandall JP, Cohen P, et al. Low insulin-like growth factor-1 level predicts survival in humans with exceptional longevity. Aging Cell. 2014;13(4):769-71.

230. Nakajima S, Ohsawa I, Ohta S, Ohno M, Mikami T. Regular voluntary exercise cures stress-induced impairment of cognitive function and cell proliferation accompanied by increases in cerebral IGF-1 and GST activity in mice. Behav Brain Res. 2010;211 (2):178-84.

231. Freude S, Hettich MM, Schumann C, Stöhr O, Koch L, Köhler C, et al. Neuronal IGF-1 resistance reduces $A \beta$ accumulation and protects against premature death in a model of Alzheimer's disease. FASEB J. 2009;23(10):3315-24.
232. Cohen E, Paulsson JF, Blinder P, Burstyn-Cohen T, Du D, Estepa G, et al. Reduced IGF-1 signaling delays age-associated proteotoxicity in mice. Cell. 2009;139(6):1157-69.

233. O'Neill C, Moloney AM, Griffin RJ, Coakley MF, Timmons S, O'Connor $R$, et al. P4-222: Defects in IGF-1 receptor, insulin receptor and insulin receptor substrate proteins in Alzheimer's disease neurons indicate resistance to insulin and IGF-1 signaling. Alzheimer's Dementia. 2008;4:T736.

234. Webb AE, Brunet A. FOXO transcription factors: key regulators of cellular quality control. Trends Biochem Sci. 2014;39(4):159-69.

235. Wang Y, Zhou Y, Graves DT. FOXO transcription factors: their clinical significance and regulation. BioMed Res Int. 2014;2014:87.

236. Klotz L-O, Sánchez-Ramos C, Prieto-Arroyo I, Urbánek P, Steinbrenner H, Monsalve M. Redox regulation of FoxO transcription factors. Redox Biol. 2015;6:51-72.

237. Martins R, Lithgow GJ, LinkW. Long live FOXO: unraveling the role of FOXO proteins in aging and longevity. Aging Cell. 2016;15(2):196-207.

238. Kenyon C. The plasticity of aging: insights from long-lived mutants. Cell. 2005;120(4):449-60.

239. Morris JZ, Tissenbaum HA, Ruvkun G. A phosphatidylinositol-3-OH kinase family member regulating longevity and diapause in Caenorhabditis elegans. Nature. 1996;382(6591):536-9.

240. Clancy DJ, Gems D, Harshman LG, Oldham S, Stocker H, Hafen E, et al. Extension of life-span by loss of CHICO, a Drosophila insulin receptor substrate protein. Science. 2001;292(5514):104-6.

241. Uno M, Nishida E. Lifespan-regulating genes in C elegans. NPJ Aging Mech Dis. 2016:2(1):1-8.

242. Yen K, Narasimhan SD, Tissenbaum HA. DAF-16/Forkhead box O transcription factor: many paths to a single Fork (head) in the road. Antioxid Redox Signal. 2011;14(4):623-34.

243. Weichhart T, Mammalian target of rapamycin: a signaling kinase for every aspect of cellular life. Methods Mol Biol. 2012;821:1-14.

244. Floyd S, Favre C, Lasorsa FM, Leahy M, Trigiante G, Stroebel P, et al. The insulin-like growth factor-I-mTOR signaling pathway induces the mitochondrial pyrimidine nucleotide carrier to promote cell growth. Mol Biol Cell. 2007;18(9):3545-55.

245. Tsang CK, Qi H, Liu LF, Zheng XFS. Targeting mammalian target of rapamycin (mTOR) for health and diseases. Drug Discov Today. 2007;12(3-4):112-24.

246. Arsham AM, Neufeld TP. Thinking globally and acting locally with TOR. Curr Opin Cell Biol. 2006;18(6):589-97.

247. Sharp ZD, Bartke A. Evidence for down-regulation of phosphoinositide 3-kinase/Akt/mammalian target of rapamycin (PI3K/Akt/mTOR)dependent translation regulatory signaling pathways in Ames dwarf mice. J Gerontol A Biol Sci Med Sci. 2005;60(3):293-300.

248. Blagosklonny MV. Aging and immortality: quasi-programmed senescence and its pharmacologic inhibition. Cell Cycle. 2006:5(18):2087-102.

249. Wullschleger S, Loewith R, Hall MN. TOR signaling in growth and metabolism. Cell. 2006;124(3):471-84.

250. Nacarelli T, Azar A, Sell C. Aberrant mTOR activation in senescence and aging: a mitochondrial stress response? Exp Gerontol. 2015;68:66-70.

251. Burkewitz K, Weir HJM, Mair WB. AMPK as a pro-longevity target. AMP Activat Protein Kinase. 2016;54:227-56.

252. Hardie DG. AMPK: positive and negative regulation, and its role in whole-body energy homeostasis. Curr Opin Cell Biol. 2015;33:1-7.

253. Hardie DG, Ross FA, Hawley SA. AMPK: a nutrient and energy sensor that maintains energy homeostasis. Nat Rev Mol Cell Biol. 2012;13(4):251-62.

254. Martin-Montalvo A, Mercken EM, Mitchell SJ, Palacios HH, Mote PL, Scheibye-Knudsen $\mathrm{M}$, et al. Metformin improves healthspan and lifespan in mice. Nat Commun. 2013;4(1):1-9.

255. Hall JA, Dominy JE, Lee Y, Puigserver P. The sirtuin family's role in aging and age-associated pathologies. J Clin Investig. 2013;123(3):973-9.

256. Haigis MC, Sinclair DA. Mammalian sirtuins: biological insights and disease relevance. Annu Rev Pathol. 2010:5:253-95.

257. Srivastava S. Emerging therapeutic roles for NAD+ metabolism in mitochondrial and age-related disorders. Clin TransI Med. 2016;5(1):1-11.

258. Kelly G. A review of the sirtuin system, its clinical implications, and the potential role of dietary activators like resveratrol: part 1. Altern Med Rev. 2010:15:3. 
259. Fröjdö S, Durand C, Molin L, Carey AL, El-Osta A, Kingwell BA, et al. Phosphoinositide 3-kinase as a novel functional target for the regulation of the insulin signaling pathway by SIRT1. Mol Cell Endocrinol. 2011;335(2):166-76

260. Xiong S, Salazar G, Patrushev N, Alexander RW. FoxO1 mediates an autofeedback loop regulating SIRT1 expression. J Biol Chem. 2011;286(7):5289-99.

261. Liu J, Zhang C, Hu W, Feng Z. Tumor suppressor p53 and its mutants in cancer metabolism. Cancer Lett. 2015;356(2):197-203.

262. Rufini A, Tucci P, Celardo I, Melino G. Senescence and aging: the critical roles of p53. Oncogene. 2013;32(43):5129-43.

263. Schwartzenberg-Bar-Yoseph F, Armoni M, Karnieli E. The tumor suppressor p53 down-regulates glucose transporters GLUT1 and GLUT4 gene expression. Can Res. 2004;64(7):2627-33.

264. Vousden KH, Ryan KM. p53 and metabolism. Nat Rev Cancer. 2009;9(10):691-700

265. Kawauchi K, Araki K, Tobiume K, Tanaka N. p53 regulates glucose metabolism through an IKK-NF-KB pathway and inhibits cell transformation. Nat Cell Biol. 2008;10(5):611-8.

266. Jiang P, Du W, Yang X. p53 and regulation of tumor metabolism. J Carcinogen. 2013;12:57.

267. Kung C-P, Murphy ME. The role of the p53 tumor suppressor in metabolism and diabetes. J Endocrinol. 2016;231(2):R61.

268. Matoba S, Kang J-G, Patino WD, Wragg A, Boehm M, Gavrilova $\mathrm{O}$, et al. p53 regulates mitochondrial respiration. Science. 2006;312(5780):1650-3.

269. Zhang $C$, Lin $M$, Wu R, Wang $X$, Yang B, Levine AJ, et al. Parkin, a p53 target gene, mediates the role of p53 in glucose metabolism and the Warburg effect. Proc Natl Acad Sci. 2011;108(39):16259-64.

270. Kruiswijk F, Labuschagne CF, Vousden KH. p53 in survival, death and metabolic health: a lifeguard with a licence to kill. Nat Rev Mol Cell Biol. 2015;16(7):393-405.

271. Berkers CR, Maddocks ODK, Cheung EC, Mor I, Vousden KH. Metabolic regulation by p53 family members. Cell Metab. 2013;18(5):617-33.

272. Owada Y, Utsunomiya A, Yoshimoto T, Kondo H. Expression of mRNA for Akt, serine-threonine protein kinase, in the brain during development and its transient enhancement following axotomy of hypoglossal nerve. J Mol Neurosci. 1997:9(1):27-33.

273. Akiyama H, Kamiguchi H. Phosphatidylinositol 3-kinase facilitates microtubule-dependent membrane transport for neuronal growth cone guidance. J Biol Chem. 2010;285(53):41740-8.

274. Sui L, Wang J, Li B-M. Role of the phosphoinositide 3-kinase-Aktmammalian target of the rapamycin signaling pathway in long-term potentiation and trace fear conditioning memory in rat medial prefrontal cortex. Learn Mem. 2008;15(10):762-76.

275. Peltier J, O'Neill A, Schaffer DV. PI3K/Akt and CREB regulate adult neural hippocampal progenitor proliferation and differentiation. Dev Neurobiol. 2007;67(10):1348-61.

276. Tully T. Regulation of gene expression and its role in long-term memory and synaptic plasticity. Proc Natl Acad Sci. 1997;94(9):4239-41.

277. Yin JCP, Del Vecchio M, Zhou H, Tully T. CREB as a memory modulator: induced expression of a dCREB2 activator isoform enhances long-term memory in Drosophila. Cell. 1995;81(1):107-15.

278. Alberini CM. Transcription factors in long-term memory and synaptic plasticity. Physiol Rev. 2009:89(1):121-45.

279. Finkbeiner S, Tavazoie SF, Maloratsky A, Jacobs KM, Harris KM, Greenberg ME. CREB: a major mediator of neuronal neurotrophin responses. Neuron. 1997;19(5):1031-47.

280. Wu Y, Deng F, Wang J, Liu Y, Zhou W, Qu L, et al. Intensity-dependent effects of consecutive treadmill exercise on spatial learning and memory through the $\mathrm{p}$-CREB/BDNF/NMDAR signaling in hippocampus. Behav Brain Res. 2020;386:112599.

281. Vaynman S, Ying Z, Gomez-Pinilla F. Hippocampal BDNF mediates the efficacy of exercise on synaptic plasticity and cognition. Eur J Neurosci. 2004;20(10):2580-90.

282. Bolton MM, Pittman AJ, Lo DC. Brain-derived neurotrophic factor differentially regulates excitatory and inhibitory synaptic transmission in hippocampal cultures. J Neurosci. 2000;20(9):3221-32.

283. Lo DC. Neurotrophic factors and synaptic plasticity. Neuron. 1995;15(5):979-81.
284. Figurov A, Pozzo-Miller LD, Olafsson P, Wang T, Lu B. Regulation of synaptic responses to high-frequency stimulation and LTP by neurotrophins in the hippocampus. Nature. 1996;381(6584):706-9.

285. Ma YL, Wang HL, Wu HC, Wei CL, Lee EHY. Brain-derived neurotrophic factor antisense oligonucleotide impairs memory retention and inhibits long-term potentiation in rats. Neuroscience. 1997;82(4):957-67.

286. Patterson SL, Abel T, Deuel TA, Martin KC, Rose JC, Kandel ER. Recombinant BDNF rescues deficits in basal synaptic transmission and hippocampal LTP in BDNF knockout mice. Neuron. 1996:16(6):1137-45.

287. Berchtold NC, Castello N, Cotman CW. Exercise and time-dependent benefits to learning and memory. Neuroscience. 2010;167(3):588-97.

288. Hariri AR, Goldberg TE, Mattay VS, Kolachana BS, Callicott JH, Egan MF, et al. Brain-derived neurotrophic factor val66met polymorphism affects human memory-related hippocampal activity and predicts memory performance. J Neurosci. 2003;23(17):6690-4.

289. Neeper SA, Gómez-Pinilla F, Choi J, Cotman C. Exercise and brain neurotrophins. Nature. 1995;373(6510):109.

290. Farmer J, Zhao X, van Praag H, Wodtke K, Gage FH, Christie BR. Effects of voluntary exercise on synaptic plasticity and gene expression in the dentate gyrus of adult male Sprague-Dawley rats in vivo. Neuroscience. 2004;124(1):71-9.

291. Connor B, Young D, Yan Q, Faull RL, Synek B, Dragunow M. Brainderived neurotrophic factor is reduced in Alzheimer's disease. Brain Res Mol Brain Res. 1997;49(1-2):71-81.

292. Adlard PA, Perreau VM, Cotman CW. The exercise-induced expression of BDNF within the hippocampus varies across life-span. Neurobiol Aging. 2005:26(4):511-20.

293. Trejo JL, Carro E, Torres-Aleman I. Circulating insulin-like growth factor I mediates exercise-induced increases in the number of new neurons in the adult hippocampus. J Neurosci. 2001;21(5):1628-34.

294. Berchtold NC, Kesslak JP, Pike CJ, Adlard PA, Cotman CW. Estrogen and exercise interact to regulate brain-derived neurotrophic factor mRNA and protein expression in the hippocampus. Eur J Neurosci. 2001;14(12):1992-2002.

295. Carro E, Nuñez A, Busiguina S, Torres-Aleman I. Circulating insulin-like growth factor I mediates effects of exercise on the brain. J Neurosci. 2000;20(8):2926-33.

296. Blomstrand E, Perrett D, Parry-Billings M, Newsholme EA. Effect of sustained exercise on plasma amino acid concentrations and on 5-hydroxytryptamine metabolism in six different brain regions in the rat. Acta Physiol Scand. 1989;136(3):473-81.

297. Fordyce DE, Starnes JW, Farrar RP. Compensation of the age-related decline in hippocampal muscarinic receptor density through daily exercise or underfeeding. J Gerontol. 1991;46(6):B245-8.

298. Lopez-Lopez C, LeRoith D, Torres-Aleman I. Insulin-like growth factor $\mathrm{I}$ is required for vessel remodeling in the adult brain. Proc Natl Acad Sci USA. 2004;101(26):9833-8.

299. Ding Y, Li J, Luan X, Ding YH, Lai Q, Rafols JA, et al. Exercise preconditioning reduces brain damage in ischemic rats that may be associated with regional angiogenesis and cellular overexpression of neurotrophin. Neuroscience. 2004;124(3):583-91.

300. Carro E, Trejo JL, Busiguina S, Torres-Aleman I. Circulating insulin-like growth factor I mediates the protective effects of physical exercise against brain insults of different etiology and anatomy. J Neurosci. 2001;21(15):5678-84.

301. Knipper M, da Penha BM, Blöchl A, Breer H, Thoenen H, Lindholm $D$. Positive feedback between acetylcholine and the neurotrophins nerve growth factor and brain-derived neurotrophic factor in the rat hippocampus. Eur J Neurosci. 1994;6(4):668-71.

302. Knüsel B, Winslow JW, Rosenthal A, Burton LE, Seid DP, Nikolics K, et al. Promotion of central cholinergic and dopaminergic neuron differentiation by brain-derived neurotrophic factor but not neurotrophin 3. Proc Natl Acad Sci USA. 1991;88(3):961-5.

303. Mohammed AH, Zhu SW, Darmopil S, Hjerling-Leffler J, Ernfors $P$, Winblad B, et al. Environmental enrichment and the brain. Prog Brain Res. 2002:138:109-33.

304. Ickes BR, Pham TM, Sanders LA, Albeck DS, Mohammed AH, Granholm A-C. Long-term environmental enrichment leads to 
regional increases in neurotrophin levels in rat brain. Exp Neurol. 2000;164(1):45-52.

305. Genoud C, Knott GW, Sakata K, Lu B, Welker E. Altered synapse formation in the adult somatosensory cortex of brain-derived neurotrophic factor heterozygote mice. J Neurosci. 2004;24(10):2394-400.

306. Spires TL, Grote HE, Varshney NK, Cordery PM, Van Dellen A, Blakemore $C$, et al. Environmental enrichment rescues protein deficits in a mouse model of Huntington's disease, indicating a possible disease mechanism. J Neurosci. 2004;24(9):2270-6.

307. Li X-Y, Zhan X-R, Liu X-M, Wang X-C. CREB is a regulatory target for the protein kinase Akt/PKB in the differentiation of pancreatic ductal cells into islet $\beta$-cells mediated by hepatocyte growth factor. Biochem Biophys Res Commun. 2011;404(2):711-6.

308. Datta SR, Dudek H, Tao X, Masters S, Fu H, Gotoh Y, et al. Akt phosphorylation of BAD couples survival signals to the cell-intrinsic death machinery. Cell. 1997;91(2):231-41.

309. Sloane JA, Hollander W, Moss MB, Rosene DL, Abraham CR. Increased microglial activation and protein nitration in white matter of the aging monkey zr. Neurobiol Aging. 1999;20(4):395-405.

310. Chong ZZ, Kang J-Q, Maiese K. AKT1 drives endothelial cell membrane asymmetry and microglial activation through $\mathrm{BCl}-\mathrm{XL}$ and caspase 1, 3, and 9. Exp Cell Res. 2004;296(2):196-207.

311. Kang J-Q, Chong ZZ, Maiese K. Critical role for Akt1 in the modulation of apoptotic phosphatidylserine exposure and microglial activation. Mol Pharmacol. 2003;64(3):557-69.

312. Crowder RJ, Freeman RS. Phosphatidylinositol 3-kinase and Akt protein kinase are necessary and sufficient for the survival of nerve growth factor-dependent sympathetic neurons. J Neurosci. 1998;18(8):2933-43.

313. Kang JQ, Chong ZZ, Maiese K. Akt1 protects against inflammatory microglial activation through maintenance of membrane asymmetry and modulation of cysteine protease activity. J Neurosci Res. 2003;74(1):37-51.

314. Murata H, Sakaguchi M, Jin Y, Sakaguchi Y, Futami J, Yamada H, et al. A new cytosolic pathway from a Parkinson disease-associated kinase, BRPK/PINK1: activation of AKT via mTORC2. J Biolo Chem. 2011;286(9):7182-9.

315. BruelJungerman E, Veyrac A, Dufour F, Horwood J, Laroche S, Davis S. Inhibition of PI3K-Akt signaling blocks exercise-mediated enhancement of adult neurogenesis and synaptic plasticity in the dentate gyrus. PloS ONE. 2009:4(11):e7901.

316. Opazo P, Watabe AM, Grant SGN, O'Dell TJ. Phosphatidylinositol 3-kinase regulates the induction of long-term potentiation through extracellular signal-related kinase-independent mechanisms. J Neurosci. 2003;23(9):3679-88

317. Horwood JM, Dufour F, Laroche S, Davis S. Signalling mechanisms mediated by the phosphoinositide 3-kinase/Akt cascade in synaptic plasticity and memory in the rat. Eur J Neurosci. 2006;23(12):3375-84

318. Lin C-H, Yeh S-H, Lin C-H, Lu K-T, Leu T-H, Chang W-C, et al. A role for the $\mathrm{Pl}-3$ kinase signaling pathway in fear conditioning and synaptic plasticity in the amygdala. Neuron. 2001;31(5):841-51.

319. Hoyer S. The aging brain. Changes in the neuronal insulin/insulin receptor signal transduction cascade trigger late-onset sporadic Alzheimer disease (SAD). A mini-review. J Neural Transmission. 2002;109(8):991-1002.

320. Zhao W, Chen H, Xu H, Moore E, Meiri N, Quon MJ, et al. Brain insulin receptors and spatial memory: correlated changes in gene expression, tyrosine phosphorylation, and signaling molecules in the hippocampus of water maze trained rats. J Biol Chem. 1999;274(49):34893-902.

321. Wang Q, Liu L, Pei L, Ju W, Ahmadian G, Lu J, et al. Control of synaptic strength, a novel function of Akt. Neuron. 2003;38(6):915-28.

322. Je HS, Ji Y, Wang Y, Yang F, Wu W, Lu B. Presynaptic protein synthesis required for NT-3-induced long-term synaptic modulation. Mol Brain. $2011 ; 4(1): 1-8$

323. Je H-S, Lu Y, Yang F, Nagappan G, Zhou J, Jiang Z, et al. Chemically inducible inactivation of protein synthesis in genetically targeted neurons. J Neurosci. 2009:29(21):6761-6.

324. Lu J, Wu D, Zheng Z, Zheng Y, Hu B, Zhang Z. Troxerutin protects against high cholesterol-induced cognitive deficits in mice. Brain 2011;134(3):783-97.

325. Flanagan EW, Most J, Mey JT, Redman LM. Calorie restriction and aging in humans. Annu Rev Nutr. 2020:40:105-33.
326. Mattson MP. Dietary factors, hormesis and health. Ageing Res Rev. 2008;7(1):43-8.

327. Mattson MP. Gene-diet interactions in brain aging and neurodegenerative disorders. Ann Internal Med. 2003;139(5):441-4.

328. Lee J, Seroogy KB, Mattson MP. Dietary restriction enhances neurotrophin expression and neurogenesis in the hippocampus of adult mice. J Neurochem. 2002:80(3):539-47.

329. Lee J, Duan W, Mattson MP. Evidence that brain-derived neurotrophic factor is required for basal neurogenesis and mediates, in part, the enhancement of neurogenesis by dietary restriction in the hippocampus of adult mice. J Neurochem. 2002;82(6):1367-75.

330. Duan W, Lee J, Guo Z, Mattson MP. Dietary restriction stimulates BDNF production in the brain and thereby protects neurons against excitotoxic injury. J Mol Neurosci. 2001;16(1):1-12.

331. Bruce-Keller AJ, Umberger G, McFall R, Mattson MP. Food restriction reduces brain damage and improves behavioral outcome following excitotoxic and metabolic insults. Ann Neurol. 1999;45(1):8-15.

332. Duan W, Mattson MP. Dietary restriction and 2-deoxyglucose administration improve behavioral outcome and reduce degeneration of dopaminergic neurons in models of Parkinson's disease. J Neurosci Res. 1999;57(2):195-206.

333. Maswood N, Young J, Tilmont E, Zhang Z, Gash DM, Gerhardt GA, et al. Caloric restriction increases neurotrophic factor levels and attenuates neurochemical and behavioral deficits in a primate model of Parkinson's disease. Proc Natl Acad Sci. 2004:101 (52):18171-6.

334. Ravagnan L, Gurbuxani S, Susin SA, Maisse C, Daugas E, Zamzami N, et al. Heat-shock protein 70 antagonizes apoptosis-inducing factor. Nat Cell Biol. 2001;3(9):839-43.

335. Frydman J. Folding of newly translated proteins in vivo: the role of molecular chaperones. Annu Rev Biochem. 2001;70(1):603-47.

336. Beere HM, Wolf BB, Cain K, Mosser DD, Mahboubi A, Kuwana T, et al. Heat-shock protein 70 inhibits apoptosis by preventing recruitment of procaspase-9 to the Apaf-1 apoptosome. Nat Cell Biol. 2000;2(8):469-75.

337. Warrick JM, Chan HYE, Gray-Board GL, Chai Y, Paulson HL, Bonini NM. Suppression of polyglutamine-mediated neurodegeneration in Drosophila by the molecular chaperone HSP70. Nat Genet. 1999:23(4):425-8.

338. Yu Z, Luo H, Fu W, Mattson MP. The endoplasmic reticulum stressresponsive protein GRP78 protects neurons against excitotoxicity and apoptosis: suppression of oxidative stress and stabilization of calcium homeostasis. Exp Neurol. 1999:155(2):302-14.

339. Lowenstein DH, Chan PH, Miles MF. The stress protein response in cultured neurons: characterization and evidence for a protective role in excitotoxicity. Neuron. 1991;7(6):1053-60.

340. Lee C-K, Klopp RG, Weindruch R, Prolla TA. Gene expression profile of aging and its retardation by caloric restriction. Science. 1999;285(5432):1390-3.

341. Yu ZF, Mattson MP. Dietary restriction and 2-deoxyglucose administration reduce focal ischemic brain damage and improve behavioral outcome: evidence for a preconditioning mechanism. J Neurosci Res. 1999;57(6):830-9

342. Mascarucci P, Taub D, Saccani S, Paloma MA, Dawson H, Roth GS, et al Cytokine responses in young and old rhesus monkeys: effect of caloric restriction. J Interferon Cytokine Res. 2002;22(5):565-71.

343. Lee J, Kim SJ, Son TG, Chan SL, Mattson MP. Interferon- $\gamma$ is up-regulated in the hippocampus in response to intermittent fasting and protects hippocampal neurons against excitotoxicity. J Neurosci Res. 2006;83(8):1552-7.

344. Masoro EJ, McCarter RJM, Katz MS, McMahan CA. Dietary restriction alters characteristics of glucose fuel use. J Gerontol. 1992;47(6):B202-8.

345. Kenyon C, Chang J, Gensch E, Rudner A, Tabtiang RAC. elegans mutant that lives twice as long as wild type. Nature. 1993;366(6454):461-4.

346. Lane MA, Ball SS, Ingram DK, Cutler RG, Engel J, Read V, et al. Diet restriction in rhesus monkeys lowers fasting and glucose-stimulated glucoregulatory end points. Am J Physiol Endocrinol Metabol. 1995;268(5):E941-8

347. Gazdag AC, Dumke CL, Kahn CR, Cartee GD. Calorie restriction increases insulin-stimulated glucose transport in skeletal muscle from IRS-1 knockout mice. Diabetes. 1999;48(10):1930-6. 
348. Kim H-J, Kim K-W, Yu B-P, Chung H-Y. The effect of age on cyclooxygenase-2 gene expression: NF-KB activation and IKBa degradation. Free Radical Biol Med. 2000;28(5):683-92.

349. Martin B, Mattson MP, Maudsley S. Caloric restriction and intermittent fasting: two potential diets for successful brain aging. Ageing Res Rev. 2006;5(3):332-53.

350. Imae M, Fu Z, Yoshida A, Noguchi T, Kato H. Nutritional and hormonal factors control the gene expression of FoxOs, the mammalian homologues of DAF-16. J Mol Endocrinol. 2003;30(2):253-62.

351. Furuyama T, Kitayama K, Yamashita H, Mori N. Forkhead transcription factor FOXO1 (FKHR)-dependent induction of PDK4 gene expression in skeletal muscle during energy deprivation. Biochem J. 2003:375(2):365-71

352. Tsuchiya T, Dhahbi JM, Cui X, Mote PL, Bartke A, Spindler SR. Additive regulation of hepatic gene expression by dwarfism and caloric restriction. Physiol Genomics. 2004;17(3):307-15.

353. Al-Regaiey KA, Masternak MM, Bonkowski M, Sun L, Bartke A. Long-lived growth hormone receptor knockout mice: interaction of reduced insulin-like growth factor i/insulin signaling and caloric restriction. Endocrinology. 2005;146(2):851-60.

354. Oh SW, Mukhopadhyay A, Svrzikapa N, Jiang F, Davis RJ, Tissenbaum HA. JNK regulates lifespan in Caenorhabditis elegans by modulating nuclear translocation of forkhead transcription factor/DAF-16. Proc Natl Acad Sci. 2005;102(12):4494-9.

355. Wang MC, Bohmann D, Jasper $H$. JNK extends life span and limits growth by antagonizing cellular and organism-wide responses to insulin signaling. Cell. 2005;121(1):115-25.

356. Ling C, Poulsen P, Carlsson E, Ridderstråle $M$, Almgren P, Wojtaszewski $J$, et al. Multiple environmental and genetic factors influence skeletal muscle PGC-1 1 and PGC-1 $\beta$ gene expression in twins. J Clin Investig. 2004;114(10):1518-26.

357. Kayo T, Allison DB, Weindruch R, Prolla TA. Influences of aging and caloric restriction on the transcriptional profile of skeletal muscle from rhesus monkeys. Proc Natl Acad Sci. 2001;98(9):5093-8.

358. Klar AJS, Fogel S, Macleod K. MAR1-A REGULATOR OF THE HM a AND HMa LOCI IN SACCHAROMYCES CEREVISIAE. Genetics. 1979;93(1):37-50.

359. Rine J, Herskowitz I. Four genes responsible for a position effect on expression from HML and HMR in Saccharomyces cerevisiae. Genetics. 1987;116(1):9-22.

360. Kennedy BK, Austriaco NR, Zhang J, Guarente L. Mutation in the silenc ing gene S/R4 can delay aging in S. cerevisiae. Cell. 1995;80(3):485-96.

361. Tissenbaum HA, Guarente L. Increased dosage of a sir-2 gene extends lifespan in Caenorhabditis elegans. Nature. 2001;410(6825):227-30.

362. Rogina B, Helfand SL. Sir2 mediates longevity in the fly through a pathway related to calorie restriction. Proc Natl Acad Sci. 2004;101(45):15998-6003.

363. Kaeberlein M, McVey M, Guarente L. The SIR2/3/4 complex and SIR2 alone promote longevity in Saccharomyces cerevisiae by two different mechanisms. Genes Dev. 1999:13(19):2570-80.

364. Qin W, Yang T, Ho L, Zhao Z, Wang J, Chen L, et al. Neuronal SIRT1 activation as a novel mechanism underlying the prevention of Alzheimer disease amyloid neuropathology by calorie restriction. J Biol Chem. 2006:281(31):21745-54

365. Yeung F, Hoberg JE, Ramsey CS, Keller MD, Jones DR, Frye RA, et al. Modulation of NF-kB-dependent transcription and cell survival by the SIRT1 deacetylase. EMBO J. 2004;23(12):2369-80.

366. Chen J, Zhou Y, Mueller-Steiner S, Chen L-F, Kwon H, Yi S, et al. SIRT1 protects against microglia-dependent amyloid- $\beta$ toxicity through inhibiting NF-kB signaling. J Biol Chem. 2005;280(48):40364-74.

367. Parker JA, Arango M, Abderrahmane S, Lambert E, Tourette C, Catoire $H_{\text {, }}$ et al. Resveratrol rescues mutant polyglutamine cytotoxicity in nematode and mammalian neurons. Nat Genet. 2005:37(4):349-50.

368. De Duve C, Wattiaux R. Functions of lysosomes. Annu Rev Physiol. 1966:28(1):435-92.

369. Rabinowitz JD, White E. Autophagy and metabolism. Science. 2010:330(6009):1344-8.

370. Kim KH, Lee M-S. Autophagy - a key player in cellular and body metabolism. Nat Rev Endocrinol. 2014;10(6):322.

371. Lenoir O, Tharaux P-L, Huber TB. Autophagy in kidney disease and aging: lessons from rodent models. Kidney Int. 2016;90(5):950-64.
372. Santambrogio L, Cuervo AM. Chasing the elusive mammalian microautophagy. Autophagy. 2011;7(6):652-4.

373. Russell RC, Yuan H-X, Guan K-L. Autophagy regulation by nutrient signaling. Cell Res. 2014;24(1):42-57.

374. Li W, Yang Q, Mao Z. Chaperone-mediated autophagy: machinery, regulation and biological consequences. Cell Mol Life Sci. 2011;68(5):749-63.

375. Sridharan S, Jain K, Basu A. Regulation of autophagy by kinases. Cancers. 2011;3(2):2630-54.

376. Jung $\mathrm{CH}$, Ro S-H, Cao J, Otto NM, Kim D-H. mTOR regulation of autophagy. FEBS Lett. 2010;584(7):1287-95.

377. Alers S, Löffler AS, Wesselborg S, Stork B. Role of AMPK-mTOR-UIk1/2 in the regulation of autophagy: cross talk, shortcuts, and feedbacks. Mol Cell Biol. 2012;32(1):2-11.

378. Xiang H, Zhang J, Lin C, Zhang L, Liu B, Ouyang L. Targeting autophagyrelated protein kinases for potential therapeutic purpose. Acta Pharmaceutica Sinica B. 2020;10(4):569-81.

379. Kroemer G, Mariño G, Levine B. Autophagy and the integrated stress response. Mol Cell. 2010;40(2):280-93.

380. Kaur J, Debnath J. Autophagy at the crossroads of catabolism and anabolism. Nat Rev Mol Cell Biol. 2015;16(8):461-72.

381. Cuervo AM, Dice JF. How do intracellular proteolytic systems change with age. Front Biosci. 1998:3:d25-43.

382. Sarkis GJ, Ashcom JD, Hawdon JM, Jacobson LA. Decline in protease activities with age in the nematode Caenorhabditis elegans. Mech Ageing Dev. 1988;45(3):191-201.

383. Demontis F, Perrimon N. FOXO/4E-BP signaling in Drosophila muscles regulates organism-wide proteostasis during aging. Cell. 2010;143(5):813-25

384. Kaushik S, Arias E, Kwon H, Lopez NM, Athonvarangkul D, Sahu S, et al Loss of autophagy in hypothalamic POMC neurons impairs lipolysis. EMBO Rep. 2012;13(3):258-65.

385. Simonsen A, Cumming RC, Brech A, Isakson P, Schubert DR, Finley KD. Promoting basal levels of autophagy in the nervous system enhances longevity and oxidant resistance in adult Drosophila. Autophagy. 2008;4(2):176-84

386. Lipinski MM, Zheng B, Lu T, Yan Z, Py BF, Ng A, et al. Genome-wide analysis reveals mechanisms modulating autophagy in normal brain aging and in Alzheimer's disease. Proc Natl Acad Sci. 2010;107(32):14164-9.

387. Loeser RF, Collins JA, Diekman BO. Ageing and the pathogenesis of osteoarthritis. Nat Rev Rheumatol. 2016;12(7):412-20.

388. Menzies FM, Fleming A, Rubinsztein DC. Compromised autophagy and neurodegenerative diseases. Nat Rev Neurosci. 2015;16(6):345-57.

389. Chang JT, Kumsta C, Hellman AB, Adams LM, Hansen M. Spatiotemporal regulation of autophagy during Caenorhabditis elegans aging. Elife. 2017;6:e18459

390. Wilhelm T, Byrne J, Medina R, Kolundžić E, Geisinger J, Hajduskova $M$, et al. Neuronal inhibition of the autophagy nucleation complex extends life span in post-reproductive C. elegans. Genes Dev. 2017:31(15):1561-72.

391. Fernández ÁF, Sebti S, Wei Y, Zou Z, Shi M, McMillan KL, et al. Disruption of the beclin 1-BCL2 autophagy regulatory complex promotes longevity in mice. Nature. 2018;558(7708):136-40.

392. Saha S, Ash PEA Gowda V, Liu L, Shirihai O, Wolozin B. Mutations in LRRK2 potentiate age-related impairment of autophagic flux. Mol Neurodegener. 2015;10(1):1-14.

393. Komatsu M, Waguri S, Chiba T, Murata S, Iwata J, Tanida I, et al. Loss of autophagy in the central nervous system causes neurodegeneration in mice. Nature. 2006;441(7095):880-4

394. Hara T, Nakamura K, Matsui M, Yamamoto A, Nakahara Y, SuzukiMigishima R, et al. Suppression of basal autophagy in neural cells causes neurodegenerative disease in mice. Nature. 2006:441(7095):885-9.

395. Triplett JC, Tramutola A, Swomley A, Kirk J, Grimes K, Lewis K, et al. Agerelated changes in the proteostasis network in the brain of the naked mole-rat: implications promoting healthy longevity. BBA Mol Basis Dis. 2015:1852(10):2213-24

396. Rodríguez-Muela N, Koga H, García-Ledo L, de la Villa P, De la Rosa EJ, Cuervo AM, et al. Balance between autophagic pathways preserves retinal homeostasis. Aging Cell. 2013;12(3):478-88.

397. De Biase D, Costagliola A, Pagano TB, Piegari G, Wojcik S, Dziewiątkowski J, et al. Amyloid precursor protein, lipofuscin accumulation and 
expression of autophagy markers in aged bovine brain. BMC Vet Res. 2017;13(1):1-9.

398. Mindell JA. Lysosomal acidification mechanisms. Annu Rev Physiol. 2012;74:69-86.

399. Colacurcio DJ, Nixon RA. Disorders of lysosomal acidification-The emerging role of $\mathrm{V}$-ATPase in aging and neurodegenerative disease. Ageing Res Rev. 2016;32:75-88.

400. Zhang S, Eitan E, Mattson MP. Early involvement of lysosome dysfunction in the degeneration of cerebral cortical neurons caused by the lipid peroxidation product 4-hydroxynonenal. J Neurochem. 2017;140(6):941-54.

401. Sulzer D, Mosharov E, Talloczy Z, Zucca FA, Simon JD, Zecca L. Neuronal pigmented autophagic vacuoles: lipofuscin, neuromelanin, and ceroid as macroautophagic responses during aging and disease. J Neurochem. 2008;106(1):24-36.

402. Tolkovsky AM. Mitophagy. BBA Mol Cell Res. 2009;1793(9):1508-15.

403. Deas E, Wood NW, Plun-Favreau H. Mitophagy and Parkinson's disease: the PINK1-parkin link. BBA Mol Cell Res. 2011;1813(4):623-33.
404. Gkikas I, Palikaras K, Tavernarakis N. The role of mitophagy in innate immunity. Front Immunol. 2018;9:1283.

405. Newman LE, Shadel GS. Pink1/Parkin link inflammation, mitochondrial stress, and neurodegeneration. J Cell Biol. 2018;217(10):3327-9.

406. Jin SM, Youle RJ. PINK1-and Parkin-mediated mitophagy at a glance. J Cell Sci. 2012;125(4):795-9.

407. Liu J, Liu W, Li R, Yang H. Mitophagy in Parkinson's disease: from pathogenesis to treatment. Cells. 2019;8(7):712.

408. Guebel DV, Torres NV. Sexual dimorphism and aging in the human hyppocampus: identification, validation, and impact of differentially expressed genes by factorial microarray and network analysis. Front Aging Neurosci. 2016;8:229.

\section{Publisher's Note}

Springer Nature remains neutral with regard to jurisdictional claims in published maps and institutional affiliations.
Ready to submit your research? Choose BMC and benefit from:

- fast, convenient online submission

- thorough peer review by experienced researchers in your field

- rapid publication on acceptance

- support for research data, including large and complex data types

- gold Open Access which fosters wider collaboration and increased citations

- maximum visibility for your research: over $100 \mathrm{M}$ website views per year

At BMC, research is always in progress.

Learn more biomedcentral.com/submissions 